\title{
Ice Roughness and Thickness Evolution on a Business Jet Airfoil
}

\author{
Stephen T. McClain ${ }^{1}$ \\ Baylor University, Waco, TX 76798-7356 \\ Mario Vargas ${ }^{2}$ \\ NASA Glenn Research Center, Cleveland, OH 44135 \\ Jen-Ching Tsao ${ }^{3}$ \\ Ohio Aerospace Institute, Cleveland, OH 44142 \\ and \\ Andy P. Broeren ${ }^{4}$ \\ NASA Glenn Research Center, Cleveland, OH 44135
}

\begin{abstract}
Experiments were performed in the Icing Research Tunnel at NASA Glenn Research Center to investigate the ice roughness and thickness evolution on a 152.4-cm (60-in.) chord business jet airfoil exposed to both Appendix $C$ and Appendix $O$ (SLD) icing conditions. The resulting measurements demonstrate that the average non-dimensional roughness and the stagnation point thickness for ice shapes with the same scale conditions are similar to those demonstrated on symmetric wings. However, the surface variations of roughness and thickness exhibit significant differences from those observed on symmetric airfoils. The source of the roughness and thickness differences is the result of surface pressure, velocity and temperature distribution differences from the suction to the pressure sides of the airfoil. LEWICE simulations are used to further investigate the influences of local collection efficiency and the local freezing fraction on the resulting ice roughness and thickness spatial variations.
\end{abstract}

\section{Nomenclature}

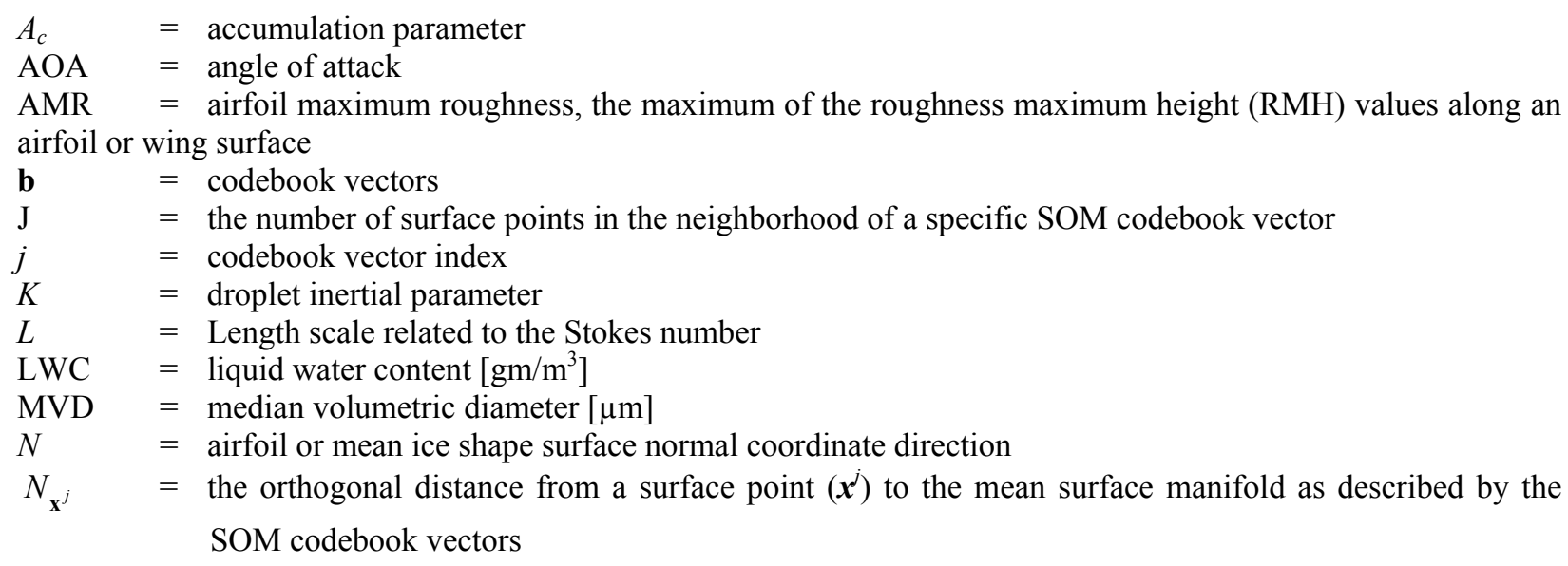

\footnotetext{
${ }^{1}$ Associate Professor, Department of Mechanical Engineering, One Bear Place \#97356, AIAA Associate Fellow

${ }^{2}$ Aerospace Engineer, Icing Branch, 21000 Brookpark Rd., AIAA Associate Fellow.

${ }^{3}$ Principal Research Scientist, Icing Branch, 21000 Brookpark Rd., AIAA Associate Fellow.

${ }^{4}$ Aerospace Engineer, Icing Branch, 21000 Brookpark Rd., AIAA Associate Fellow.
} 


$\begin{array}{ll}N_{0, R} & =\text { Fully-dense rime ice stagnation thickness on unswept wings } \\ N_{\Lambda, R} & =\text { Fully-dense rime ice surface-orthogonal thickness on swept wings } \\ \bar{N}_{0} & =\text { the measured ice orthogonal-thickness at each codebook vector relative to the clean wing surface } \\ n & =\text { stagnation point freezing fraction } \\ R M H & =99 \% \text {-Gaussian roughness maximum height evaluated at each codebook vector }\left(=3.09 R_{q}\right) \\ R_{q} & =\text { the root-mean-square or "standard deviation" roughness height } \\ r_{a} & =\text { leading edge radius of curvature } \\ \mathrm{SOM} & =\text { Self-Organizing Map } \\ S & =\text { mean ice shape surface tangential coordinate direction } \\ S_{0} & =\text { the clean airfoil tangential coordinate direction and distance } \\ T_{\text {static }} & =\text { the freestream static temperature } \\ T_{\text {total }} & =\text { the freestream stagnation or total temperature } \\ V \text { or } U_{\infty} & =\text { Freestream velocity } \\ \mathbf{x} & =\text { element of point cloud data set } \\ x & =\text { a random variable } \\ \alpha & =\text { local direction angle of manifold through a codebook vector or airfoil angle of attack } \\ \beta_{s} & =\text { local surface collection efficiency } \\ \beta_{0} & =\text { straight wing stagnation collection efficiency } \\ \gamma & =\text { direction angle of surface point relative to manifold direction through winning codebook vector } \\ \gamma_{s} & =\text { direction angle of a surface point relative to the airfoil design coordinates } \\ \Delta t_{s} & =\text { the ice accretion event time } \\ \Lambda & =\text { Sweep angle } \\ \rho_{\text {ice }} & =\text { density of ice } \\ \rho_{w} & =\text { density of liquid water } \\ \sigma & =\text { Scaled position parameter } \\ \tau & =\text { Scaled time parameter } \\ \mu_{\text {air }} & =\text { viscosity of air }\end{array}$

\section{Introduction}

Recent studies have been performed in the Icing Research Tunnel (IRT) at NASA Glenn Research Center focusing on the evolution, spatial variations, and proper scaling of ice roughness on symmetric, NACA 0012, airfoils with $0^{\circ}$ angle of attack. In these resent studies, the airfoils were exposed to icing conditions similar to those used in classical roughness studies [1-3] performed in the IRT. However, unlike the classical roughness studies, which used image analysis for roughness element morphological characterizations, the modern roughness investigations used three-dimensional laser scanning $[4,5]$ and the self-organizing map (SOM) approach of McClain and Kreeger [6] to characterize roughness statistical variations along the airfoil surface.

Using laser scanning and the SOM approach, the studies of McClain et al. [7] and McClain et al. [8] investigated roughness evolution using Appendix C [9] and super-cooled large droplet (SLD) [10] conditions, respectively, on an unswept NACA 0012 with a 53.3-cm (21-in.) chord. McClain et al. [11] presented the results of a scaling study comparing roughness on an unswept $53.3-\mathrm{cm}(21-\mathrm{in}$.) NACA 0012 to that on an unswept $182.9-\mathrm{cm}$ (72-in.) NACA 0012 airfoil in Weber number matched conditions. Most recently, McClain et al. [12] presented roughness evolution and scaling results for a $91.44-\mathrm{cm}$ (36-in.) NACA 0012 airfoil with a $30^{\circ}$-sweep.

While the results of the recent laser-scanning based roughness measurements illuminated many aspects of roughness evolution and spatial variations along the airfoils with the symmetric NACA 0012 shape, the NACA 0012 shape is not common for wings of current or future generation commercial transport aircraft. The NASA Advanced Air Transport Technology (AATT) Project and the preceding Subsonic Fixed Wing (SFW) Project have identified technologies, metrics, and goals for the reduction of energy costs, atmospheric pollution, and noise pollution for future generations of commercial air vehicles, these generations being designated $\mathrm{N}+2$ and $\mathrm{N}+3$ [13-15]. As part of projects funded through the SFW and the AATT, several specific design concepts have been explored for N +2 and $\mathrm{N}+3$ vehicles such as the truss-braced-wing (TBW) [16-18], the D8 designed by MIT [19-21], and Hybrid or Blended-wing type vehicles [22-24]. Each of these N+2 and N+3 vehicles is expected to have an advanced airfoil shape such as a natural laminar flow airfoil or a supercritical airfoil. To assist in the design of ice protection systems for the future generation aircraft, roughness evolution studies are required on airfoil shapes geometrically similar to 
wing shapes expected for future generation aircraft or producing similar aerodynamic effects to those expected on future generation aircraft.

For this study, experiments were performed in the IRT to investigate the ice roughness and thickness evolution on a 152.4-cm (60-in.) chord business-jet airfoil model. The airfoil used in the investigation was initially designed for use with small, swept-wing business jets, and the wind-tunnel model employed, which is designated as the HAARP-II model, was constructed to investigate hot air anti-icing systems [25]. The design coordinates of the HAARP-II model are presented in Figure 1. While simulations or experiments have not been published that demonstrate supercritical performance of the HAARP-II airfoil, Figure 1 demonstrates that the HAARP-II airfoil exhibits characteristics of supercritical airfoils such as a nearly-flat top (extrados) surface and a bottom (intrados) surface with an aft cusp. Consequently, the geometric characteristics of the airfoil used are similar to the supercritical wing geometries expected for future-generation $(\mathrm{N}+2$ and $\mathrm{N}+3)$ aircraft.

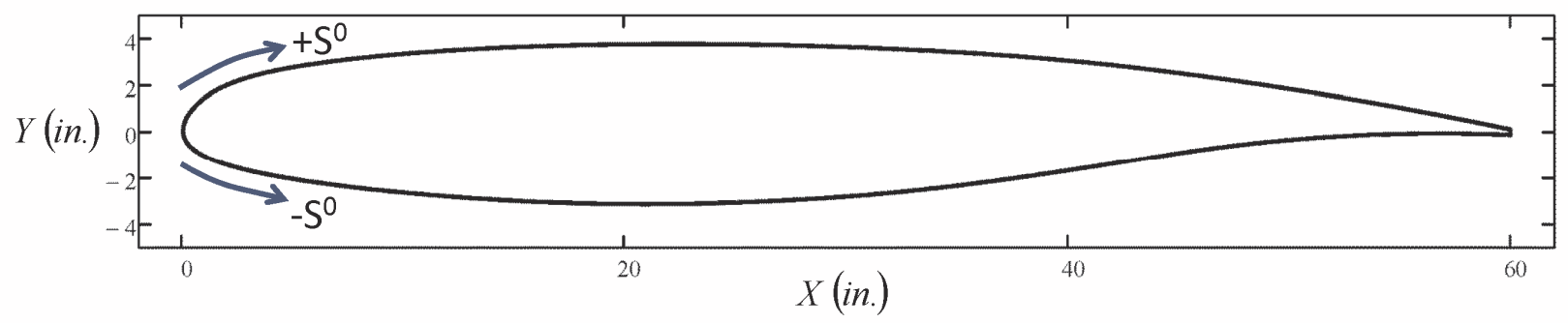

Figure 1. HAARP-II Airfoil Coordinates and Designation of Clean Surface Direction Coordinates

The HAARP-II airfoil was exposed to both Appendix C and Appendix O (SLD) icing conditions based on the conditions used for the prior NACA 0012 investigations using laser scanning. To compare the resulting roughness evolution measurements to the prior roughness measurements on NACA 0012 airfoils, the tests were performed for the non-lifting airfoil angle of attack of $-1.9^{\circ}$. At any other angle of attack, the airfoil shape will impose a circulation in the inviscid freestream flow, which will affect the droplet collection efficiency variation along the surface. By employing the non-lifting angle of attack, the experiments focus on the effects of surface geometry relative to the incoming flow as circulation is minimized.

\section{Roughness Scaling Concepts}

Scaling concepts based on the approach of Ruff [26] and following the development of Tsao and Lee [27] and Tsao and Kreeger [28] are used to compare spatial and temporal ice accretion variations to those found on airfoils of different sizes. In the scaling approach, the chord-Reynolds number and the liquid-water density-based Weber number are important. However, because of the importance of the droplet collection physics, the first parameter employed in the roughness modeling approach is the Langmuir and Blodgett [29] stagnation point collection efficiency, $\beta_{0}$, where

$$
\beta_{0}=\frac{1.4\left(K_{0}-\frac{1}{8}\right)}{1+1.4\left(K_{0}-\frac{1}{8}\right)}
$$

In Eq. (1), $K_{0}$ is the modified inertia parameter of Langmuir and Blodgett [29], defined in Eq. (2),

$$
K_{0}=\frac{1}{8}+\frac{\lambda}{\lambda_{S k}}\left(K-\frac{1}{8}\right)
$$

which is based on the droplet inertia parameter, $K$, defined in Eq. (3), 


$$
K=\frac{\rho_{w} U_{\infty} M V D^{2}}{18 \mu_{\text {air }} r_{a}}
$$

and the parameter $\lambda / \lambda_{S k}$ is the droplet range parameter and is further defined as a function of the droplet Reynolds number, $\operatorname{Re}_{\delta}=\rho V M V D / \mu$, as

$$
\frac{\lambda}{\lambda_{S k}}=\frac{1}{0.8388+0.001483 \operatorname{Re}_{\delta}+0.01847 \sqrt{\operatorname{Re}_{\delta}}}
$$

In the prior investigations of ice roughness evolution on NACA 0012 airfoils, the local surface collection efficiency was estimated using the projected area calculations, as shown in Eq. (5).

$$
\beta_{s}=\beta_{0} \cos \left(\gamma_{s}+A O A\right) \cos (\Lambda)
$$

In Eq. (5), $\Lambda$ is the wing sweep angle, AOA is the angle of attack, and $\gamma_{s}$ is the angle of the surface relative to the $\mathrm{x}$ direction axis in the airfoil design coordinates. Use of Eq. (5) assumes that the leading edge of the airfoil in the design coordinates is the location along the surface of the airfoil that experiences the stagnation point collection efficiency. For an asymmetric airfoil experiencing a no-lift condition, the location of the stagnation point is not typically the geometric leading edge in design coordinates.

For this study, LEWICE was used to generate the local collection efficiencies along the surface of the HAARPII airfoil for each distinct case investigated. For each LEWICE simulation, water drop collection efficiencies were calculated using LEWICE version 3.2 [30] for each distinct aerodynamic and icing condition. LEWICE was only run for a single time step in order to compute the drop trajectories, impingement characteristics and freezing fraction based upon the clean airfoil geometry. The SLD splashing model was used for these calculations since many of the conditions contained large drops. A 7-bin drop-size distribution was used for each case based upon the NASA IRT icing cloud calibration report [31]. The resulting local collection efficiency and freezing fraction information was then used in the subsequent analysis of the experimental data.

Figure 2 presents the LEWICE local collection efficiency results, for one of the six unique cases of cloud and airfoil conditions investigated in the study. Figure 2 demonstrates that the maximum collection efficiency occurs near the leading edge of the airfoil and then decreases as the streamwise surface distance from the leading edge increases. Figure 2 also presents the local freezing fraction (n), computed by LEWICE along the surface of the airfoil. Figure 2 demonstrates that on the initial clean airfoil surface in glaze conditions $\left(n_{0}=0.217\right)$, LEWICE indicates that the freezing fraction exhibits local maximum at the stagnation point and then approaches a value of 1.0 abruptly on both sides (top and bottom) of the airfoil surface.

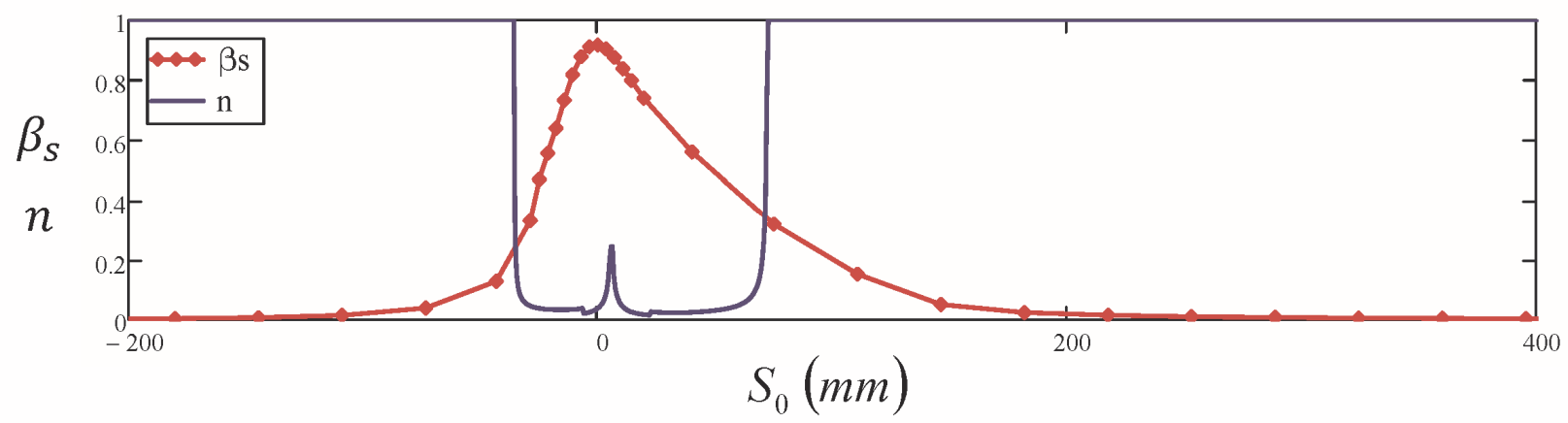

Figure 2. Example LEWICE Collection Efficiency and Freezing Fraction Results Employed in the Surface Roughness Analyses (SLD Cases $(M V D=150 \mu m)$ : 012417.05-012417.08)

To correlate temporal variations in ice roughness and ice thickness, a reference ice thickness must be developed. Using the stagnation point collection efficiency, the volume of water impinging on an incremental area centered on the leading edge of a wing with sweep angle $\Lambda$ during an ice accretion event of time $\Delta t_{s}$ may be evaluated as

4

American Institute of Aeronautics and Astronautics 


$$
d V_{\text {ice }}=\frac{L W C \cdot V \cdot \beta_{0} \cdot \Delta t_{s}}{\rho_{\text {ice }}} d A \cos (\Lambda)
$$

Dividing by the incremental area and multiplying by $2 r_{0} / 2 r_{0}$ results in what may be referred to as the leading edge, fully-dense, ideal rime ice $(n=1)$ thickness, $N_{\Lambda, R}$.

$$
N_{\Lambda, R}=\frac{L W C \cdot V \cdot \beta_{0} \cdot \Delta t_{s}}{\rho_{\text {ice }}} \frac{2 r_{0}}{2 r_{0}} \cos (\Lambda)=2 r_{0} A_{c} \beta_{0} \cos (\Lambda)
$$

where $A_{c}$ is the unswept-wing, accumulation parameter defined as

$$
A_{c}=\frac{L W C \cdot V \cdot \Delta t_{s}}{2 r_{0} \cdot \rho_{\text {ice }}}
$$

\section{Methodology}

To investigate ice roughness and thickness evolution on a business-jet airfoil and their similarities to roughness and thickness evolution on symmetric airfoils, the ice shapes were 1) created, 2) measured using three-dimensional laser scanning, and then 3) characterized using the SOM approaches of McClain and Kreeger [6] and McClain [30]. The following sections describe each of the ice roughness generation and characterization steps.

\section{A. Ice Shape Generation}

All of the experimental measurements were performed in the IRT over two nights of testing. A 152.4-cm (60in.) chord HAARP-II airfoil was used for the study. The airfoil spanned the entire 182.9-cm (72-in) height of the IRT test section. One of the nights of testing was devoted to Appendix $\mathrm{C}$ conditions, and the other night was devoted to Appendix O or supercooled large droplet (SLD) icing conditions and a set of conditions that were Weber number scaled to the conditions employed by McClain et al. [11].

The flow conditions chosen for the Appendix $\mathrm{C}$ tests were essentially the same conditions employed by Anderson et al. [3] in the historical studies of ice roughness on unswept wings with a fixed MVD of $30 \mu \mathrm{m}$. Table 1 presents the total temperatures, the freestream velocity, the median volumetric diameter, the liquid water content, the accumulation parameter, the freezing fraction, and the stagnation point collection efficiency. As shown in Table 1, the primary experimental dimension varied during each night of testing was the ice accretion time resulting in accumulation parameters ranging from 0.08 to 0.36 . Table 2 presents the cases for the SLD tests. All of the SLD tests were performed using an MVD of $150 \mu \mathrm{m}$.

Table 3 presents the cases for the Weber-number scaled cases. These cases all employ a leading-edge diameter Weber number, $W e_{d}$, of $2.36 \times 10^{6}$, a freezing fraction 0.25 , and accumulation parameters of 0.348 . The MVDs and LWC were then selected to match the stagnation point collection efficiencies employed in the McClain et al. [11] investigation of straight, 21-in. chord and 72-in. chord NACA 0012 airfoils. As shown in Table 3, the stagnation point collection efficiencies of the $W e_{d}$-matched cases ranges from 0.709 to 0.925 .

For each test, the airspeed and freestream total temperature were set and the spray bar air and water pressures were selected to provide the appropriate LWC, MVD, and freezing fraction. Two thermocouples, one embedded in the NACA 0012 airfoil and one attached to the surface of the airfoil downstream of the attachment line, were used to determine when the airfoil had reached thermal equilibrium with the flow. Once sufficient thermal equilibrium with the flow was reached, the spray bars were actuated and closed after the predetermined spray time.

Table 1. Summary of Test Parameters for the Appendix C Tests

\begin{tabular}{|c|c|c|c|c|c|c|c|c|c|}
\hline $\begin{array}{c}\text { Case } \\
\text { Number }\end{array}$ & $\begin{array}{c}\text { AoA } \\
\mathbf{d e g}\end{array}$ & $\begin{array}{c}\boldsymbol{T}_{\text {total }} \\
\left({ }^{\circ} \mathbf{C}\right)\end{array}$ & $\begin{array}{c}\mathbf{V} \\
(\mathbf{m} / \mathbf{s})\end{array}$ & $\begin{array}{c}\mathbf{M V D} \\
(\boldsymbol{\mu m})\end{array}$ & $\begin{array}{c}\mathbf{L W C} \\
\left(\mathbf{g m} / \mathbf{m}^{\mathbf{3}}\right)\end{array}$ & $\begin{array}{c}\Delta \boldsymbol{t}_{\boldsymbol{s}} \\
(\mathbf{s e c})\end{array}$ & $\boldsymbol{A}_{\boldsymbol{c}}$ & $\boldsymbol{n}$ & $\boldsymbol{\beta}_{\boldsymbol{0}}$ \\
\hline 012317.01 & -1.9 & -2.6 & 66.9 & 29.5 & 0.6 & 85 & 0.080 & 0.217 & 0.618 \\
\hline 012317.02 & -1.9 & -2.6 & 66.9 & 29.5 & 0.6 & 169 & 0.160 & 0.217 & 0.618 \\
\hline 012317.03 & -1.9 & -2.6 & 66.9 & 29.5 & 0.6 & 254 & 0.240 & 0.217 & 0.618 \\
\hline 012317.04 & -1.9 & -2.6 & 66.9 & 29.5 & 0.6 & 381 & 0.360 & 0.217 & 0.618 \\
\hline
\end{tabular}

5

American Institute of Aeronautics and Astronautics 
Table 2. Summary of Test Parameters for the SLD Tests

\begin{tabular}{|c|c|c|c|c|c|c|c|c|c|}
\hline $\begin{array}{c}\text { Case } \\
\text { Number }\end{array}$ & $\begin{array}{c}\text { AoA } \\
\mathbf{d e g}\end{array}$ & $\begin{array}{c}\boldsymbol{T}_{\text {total }} \\
\left({ }^{\circ} \mathbf{C}\right)\end{array}$ & $\begin{array}{c}\mathbf{V} \\
(\mathbf{m} / \mathbf{s})\end{array}$ & $\begin{array}{c}\mathbf{M V D} \\
(\boldsymbol{\mu \mathbf { m } )})\end{array}$ & $\begin{array}{c}\mathbf{L W C} \\
\left(\mathbf{g m} / \mathbf{m}^{\mathbf{3}}\right)\end{array}$ & $\begin{array}{c}\Delta \boldsymbol{t}_{\boldsymbol{s}} \\
(\mathbf{s e c})\end{array}$ & $\boldsymbol{A}_{\boldsymbol{c}}$ & $\boldsymbol{n}$ & $\boldsymbol{\beta}_{\boldsymbol{0}}$ \\
\hline 012417.05 & -1.9 & -3.8 & 66.9 & 150 & 0.6 & 85 & 0.080 & 0.217 & 0.932 \\
\hline 012417.06 & -1.9 & -3.8 & 66.9 & 150 & 0.6 & 169 & 0.160 & 0.217 & 0.932 \\
\hline 012417.07 & -1.9 & -3.8 & 66.9 & 150 & 0.6 & 254 & 0.240 & 0.217 & 0.932 \\
\hline 012417.08 & -1.9 & -3.8 & 66.9 & 150 & 0.6 & 381 & 0.360 & 0.217 & 0.932 \\
\hline
\end{tabular}

Table 3. Summary of Test Parameters for the Scaling Cases

\begin{tabular}{|c|c|c|c|c|c|c|c|c|c|}
\hline $\begin{array}{c}\text { Case } \\
\text { Number }\end{array}$ & $\begin{array}{c}\text { AoA } \\
\mathbf{d e g}\end{array}$ & $\begin{array}{c}\boldsymbol{T}_{\text {total }} \\
\left({ }^{\circ} \mathbf{C}\right)\end{array}$ & $\begin{array}{c}\mathbf{V} \\
(\mathbf{m} / \mathbf{s})\end{array}$ & $\begin{array}{c}\mathbf{M V D} \\
(\boldsymbol{\mu m})\end{array}$ & $\begin{array}{c}\mathbf{L W C} \\
\left(\mathbf{g m} / \mathbf{m}^{\mathbf{3}}\right)\end{array}$ & $\begin{array}{c}\Delta \boldsymbol{t}_{\boldsymbol{s}} \\
(\mathbf{s e c})\end{array}$ & $\boldsymbol{A}_{\boldsymbol{c}}$ & $\boldsymbol{n}$ & $\boldsymbol{\beta}_{\boldsymbol{0}}$ \\
\hline 012417.01 & -1.9 & -2.9 & 57.6 & 42 & 0.50 & 511.8 & 0.348 & 0.250 & 0.709 \\
\hline 012417.02 & -1.9 & -3.6 & 57.6 & 84 & 0.50 & 511.8 & 0.348 & 0.250 & 0.859 \\
\hline 012417.03 & -1.9 & -4.3 & 57.6 & 124 & 0.58 & 441.6 & 0.348 & 0.250 & 0.911 \\
\hline 012417.04 & -1.9 & -4.8 & 57.6 & 144 & 0.65 & 394.2 & 0.348 & 0.250 & 0.925 \\
\hline
\end{tabular}

\section{B. Ice Shape Measurement}

Following the completion of the icing spray, the wind tunnel velocity was reduced to less than $10 \mathrm{knots}(5 \mathrm{~m} / \mathrm{s})$ while keeping the static temperature around $-4{ }^{\circ} \mathrm{C}$ to avoid thawing of the ice shape. The iced airfoil was painted using a tetrahydrofuran (THF)-based titanium dioxide paint. A ROMER Absolute Arm laser scanning system was placed in the IRT test section upstream of the airfoil. A scan was then made of the leading $200 \mathrm{~mm}$ to $400 \mathrm{~mm}$ length of the airfoil (in the streamwise direction) on both sides of the airfoil downstream of the leading edge. The scans were approximately $150-\mathrm{mm}$ wide (in the spanwise direction) and were performed at the location of the airfoil corresponding to the center of the test section.

\section{SOM Roughness and Thickness Evaluation}

The surface point clouds were then processed using the Self-Organizing Map (SOM) approach developed by McClain and Kreeger [6]. The self-organizing map, or sometimes referred to as a Kohonen Map, is a clustering method for the detection of non-linear manifolds, which may be curves or surfaces, in multi-dimensional space [32]. SOMs depend on the use of codebook vectors, $\mathbf{b}$, which may also be called codebook points or neurons, to represent clumps of data. Following convergence of the SOM method, each codebook vector will be located at the spatial centroid of the clump of data that it represents.

When applied to an iced airfoil point cloud without sweep or significant spanwise shape changes, the SOM is expected to identify a curve in the Chord-Chord Normal plane (or X-Y plane when the spanwise axis is placed in the z-direction), which represents the mean shape of the rough airfoil. The nature of the SOM method and the positioning of the codebook vectors along a "daisy-chain" enable a statistical evaluation of iced airfoil surface roughness. Since the "clumps" of points are distributed about the codebook vectors, the deviations of the point measurements in the clumps can be used to evaluate the coverage statistics and uncertainty of the codebook vector representation.

Figure 3 shows a single surface measurement, $\mathbf{x}^{\mathrm{j}}$, and its closest codebook vector $\mathbf{b}^{\mathbf{n}}$. The two neighboring codebook vectors along the daisy-chain of codebook vectors representing the manifold are also shown. In the approach used for this study, the manifold is assumed to be a first-order manifold in two-dimensional space with the characteristic that at each codebook vector the local slope of the manifold is equal to the central finite-difference evaluated using the two closest surrounding codebook vectors. The approach used assumes that all deviations from the manifold are normal to the manifold. That is, the deviation of a surface measurement normal to the line through the codebook vector with the local slope set by the neighboring codebook vectors is considered the "height" of the surface point above or below the local manifold. 


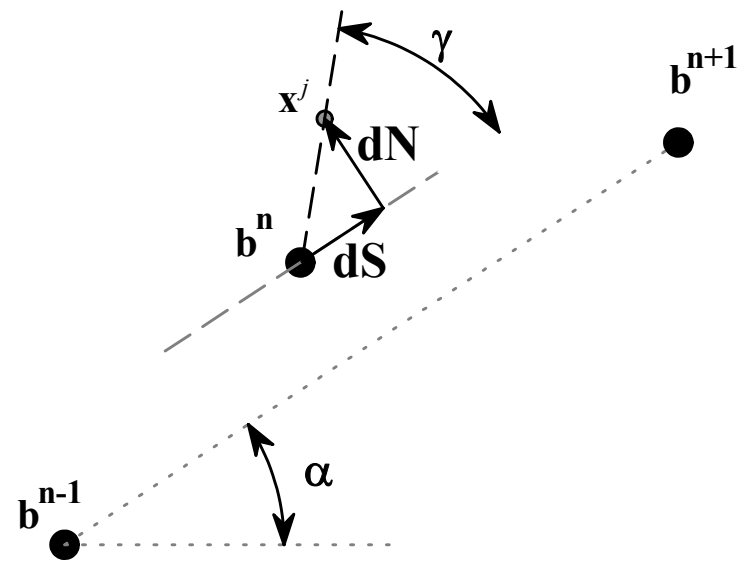

Figure 3. Metrics of Local Point about a Codebook Vector [6]

Based on the SOM-manifold description, the root-mean-square roughness height is calculated at each codebook vector as

$$
R_{q}=\left[\frac{1}{J} \sum_{j=1}^{J} N_{\mathbf{x}^{j}}{ }^{2}\right]^{\frac{1}{2}}
$$

The $99.9 \%$ roughness maximum height (RMH) based on a Gaussian distribution is calculated using 3.09 times the root-mean-square roughness height.

$$
R M H_{\mathbf{b}^{\mathbf{n}}}=3.09 R_{q}=3.09\left[\frac{1}{J} \sum_{j=1}^{J} N_{\mathbf{x}^{j}}\right]^{\frac{1}{2}}
$$

Where $J$ is the number of surface points for which $\mathbf{b}^{\mathbf{n}}$ is the winning (closest) codebook vector. The RMH is the local 99.9\%-maximum roughness height and is evaluated at each codebook vector based on the local or neighborhood statistics. The RMH will vary along the surface arc length. While the RMH is not a universal roughness descriptor, the RMH value is important for this study. Since the RMH represents a Gaussian prediction of the $99.9 \%$ maximum distance from the mean elevation to the tallest peaks in a data set, the RMH is a reasonable tool to compare the statistical results to the morphological descriptors such as roughness element diameter and height used in the historical roughness studies. More details regarding the roughness evaluation and the associated measurement uncertainties may be found in McClain [33].

The ice thickness relative to the clean airfoil shape, $N_{0 x}{ }^{j}$, is calculated in a fashion very similar to the ice roughness height, as demonstrated in Figure 4, with the exception of instead of using the codebook vector as the surface reference, the original airfoil design coordinates are used. Once the thickness at each point in the ice-shape point cloud is determined, the mean thickness evaluated at each codebook vector, $\bar{N}_{0, b^{\mathrm{n}}}$, is simply evaluated by determining the minimum orthogonal distance of the codebook vector to the clean airfoil surface. Further details regarding the ice thickness evaluation may be found in McClain [33].

The point clouds were analyzed using the Airfoil Roughness Evaluation System (ARES), which was developed to automate the roughness characterization approach of McClain and Kreeger [6]. The approach of McClain and Kreeger [6] was originally implemented using multiple software tools. ARES is a set of Matlab functions that performs the SOM characterization of the mean ice shape and then performs the two-dimensional statistical analyses required to characterize the roughness variations along the airfoil surface in the flow direction. 


\section{Results and Discussion}

The results of the investigation are divided into four subsections: (1) surface/point cloud visualization, (2) App. C and SLD temporal scaling, (3) temporal scaling for the Weber number scaled cases, and (4) spatial scaling for all of the cases.

\section{A. Point Cloud Visualization}

Figure 4 presents a visualization of Appendix C and SLD point clouds at the same accumulation parameter $\left(A_{c}\right)$ of 0.36 based on the thickness of the ice above the clean airfoil surface. The difference in roughness and the difference in the extents along the airfoil surface caused by the difference in median droplet sizes is significant. Figure 4 also demonstrates the significant differences between the top and bottom surfaces of the airfoil for each case.

\section{B. Temporal Variations in Appendix C and SLD Conditions}

Figure 5 presents the evolution of the RMS roughness height variations for both the Appendix C and the SLD conditions. The evolution of the mean ice thickness variations are presented in Figure 6. As noted in the point cloud visualization, the most significant aspect of the roughness variations and temporal development relative to the symmetric airfoils is the asymmetry in the roughness and thickness profiles in Figures 5 and 6 . Since the model is pitched downward ( $-1.9^{\circ}$ angle of attack), the roughness extends further along the top (extrados) surface of the model, but the largest values of thickness and roughness are exhibited on the bottom (intrados) surface of the model. As noted in Figure 6, the plateau region, designated as the region between the two local maxima before a rapid decay in thickness, is offset from the geometric leading edge of the airfoil.

The effect of the larger droplet size from the SLD cases compared to the Appendix C cases is evident in Figures 5 and 6, just as it was apparent in Figure 4. The larger droplets produce higher collection efficiencies along the surface of the airfoil model, and consequently, the extents of the roughness and thickness regions are expanded down the length of the airfoil model surface.

In addition to the line plots of Figure 6, Figure 7 presents the thickness of the ice projected onto the airfoil surface. Figure 7 represents the classical way of visualizing mean ice thickness measurements. The thickness and roughness may be combined with the roughness maximum height measurements to represent $99.9 \%$-inclusion limits for each airfoil shape using

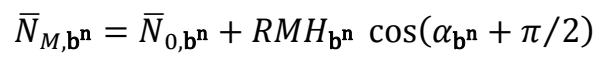

The 99.9\%-inclusion limits are presented in Figure 8 and are the SOM approach equivalent of the "maximum combined cross-section" parameter used by [34] to describe large three-dimensional ice shapes such as feathers and scallops.

To investigate the temporal scaling of the ice measurements, the roughness and thickness measurements were divided by the ideal rime ice thickness of Eq. (7). Figure 9 presents the relative roughness measurements along the surface of the airfoil, while Figure 10 presents the relative thickness measurements. Figure 9 demonstrates that the roughness profiles collapse for the Appendix C cases. Regarding the SLD cases, the roughness profiles collapse in the plateau region near the leading edge and between the locations of maximum roughness on either side of the airfoil. Outside the peaks of maximum roughness, the profiles do not collapse as well especially on the top surface $(+\mathrm{S}$ side of the figure). Figure 10 demonstrates that the ideal rime thickness scaling collapses the thickness measurements for both Appendix C and SLD cases.

\section{Temporal Scaling for the Weber Number Matched Cases}

The unscaled roughness and thickness variations along the surface of the HAARP-II model are presented in Figure 11 for the $W e_{d}$-matched cases. The temporally scaled roughness and thickness values (the roughness and thickness measurements divided by the ideal rime-ice thickness) are presented in Figure 12. Figure 12 demonstrates that inside the plateau region of the ice shapes, the roughness and thickness variations collapse when scaled using the ideal rime-ice thickness as a scaling parameter. However, outside of the plateau regions, the different collection efficiencies produce significant variations in relative roughness and thickness along the surface of the model. 

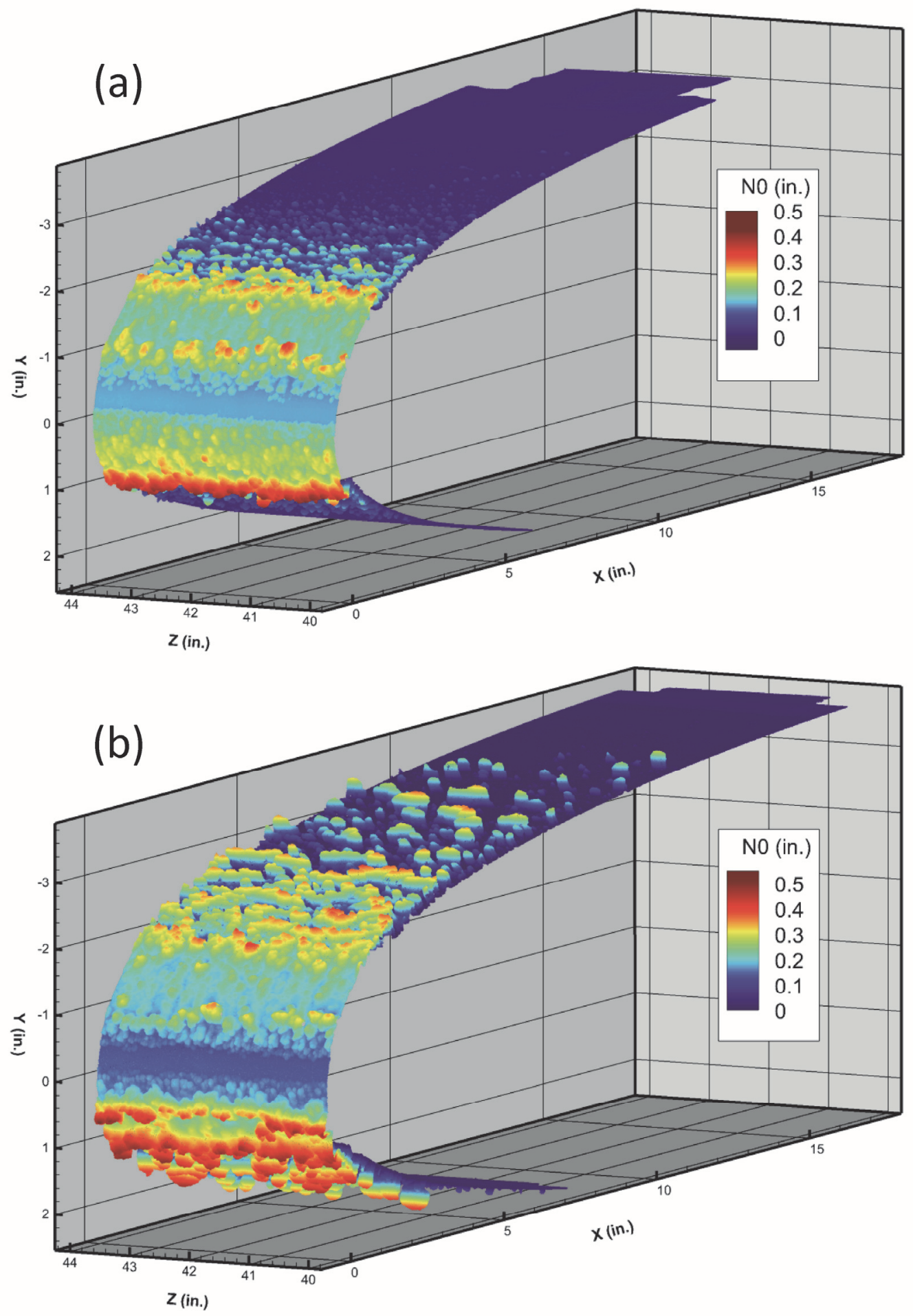

Figure 4. Visualization of Point Cloud Thickness Topography from Appendix C and SLD Cases at the Same Accumulation Parameter of 0.36: (a) 012317.04 (App.C) and (b) 012417.08 (SLD) 


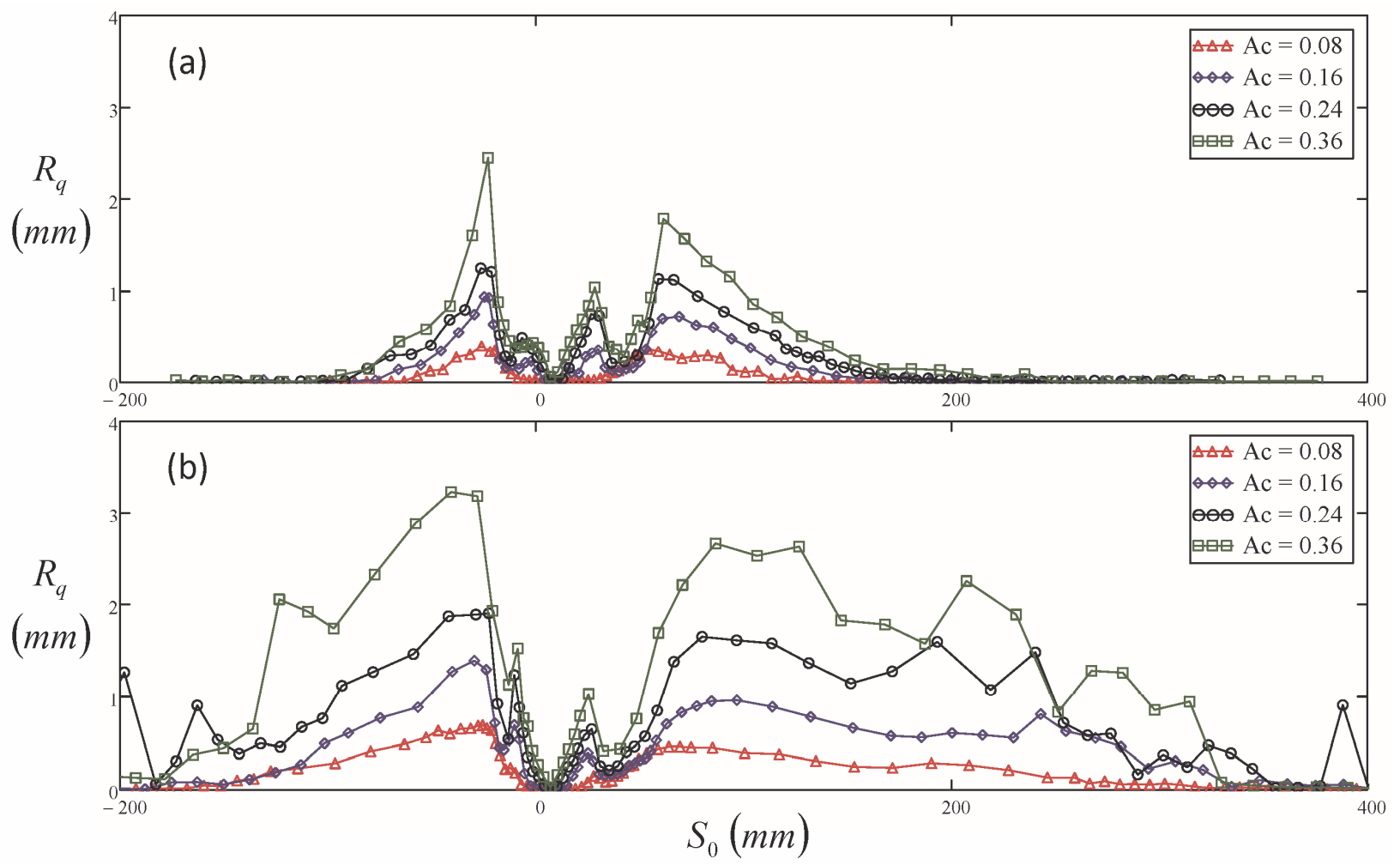

Figure 5. RMS Surface Roughness Variations along the Surface of the HAARP-II Airfoil: (a) Appendix C and (b) $S L D$
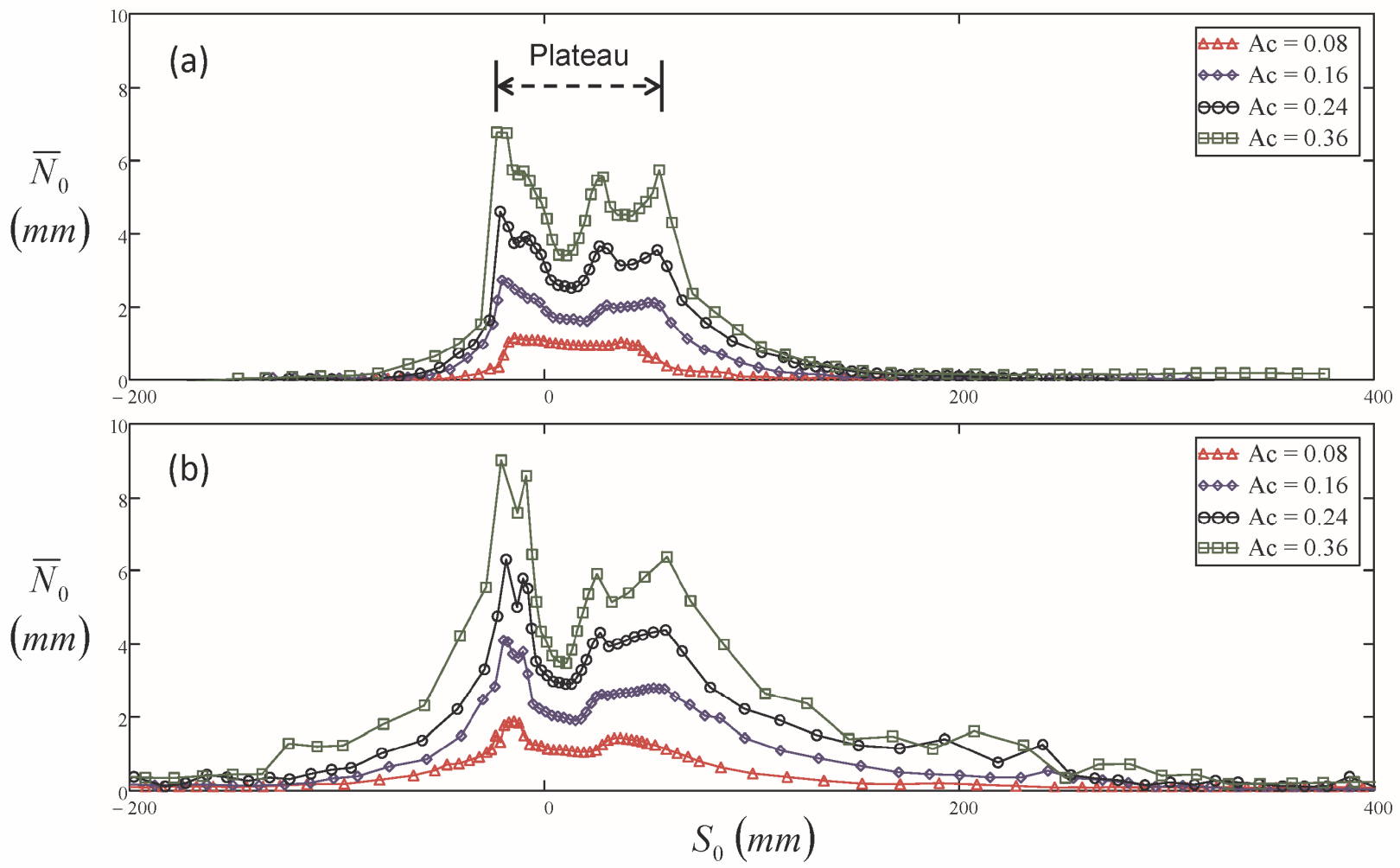

Figure 6. Mean Ice Thickness Variations along the Surface of the HAARP-II Airfoil: (a) Appendix C and (b) SLD

10

American Institute of Aeronautics and Astronautics 

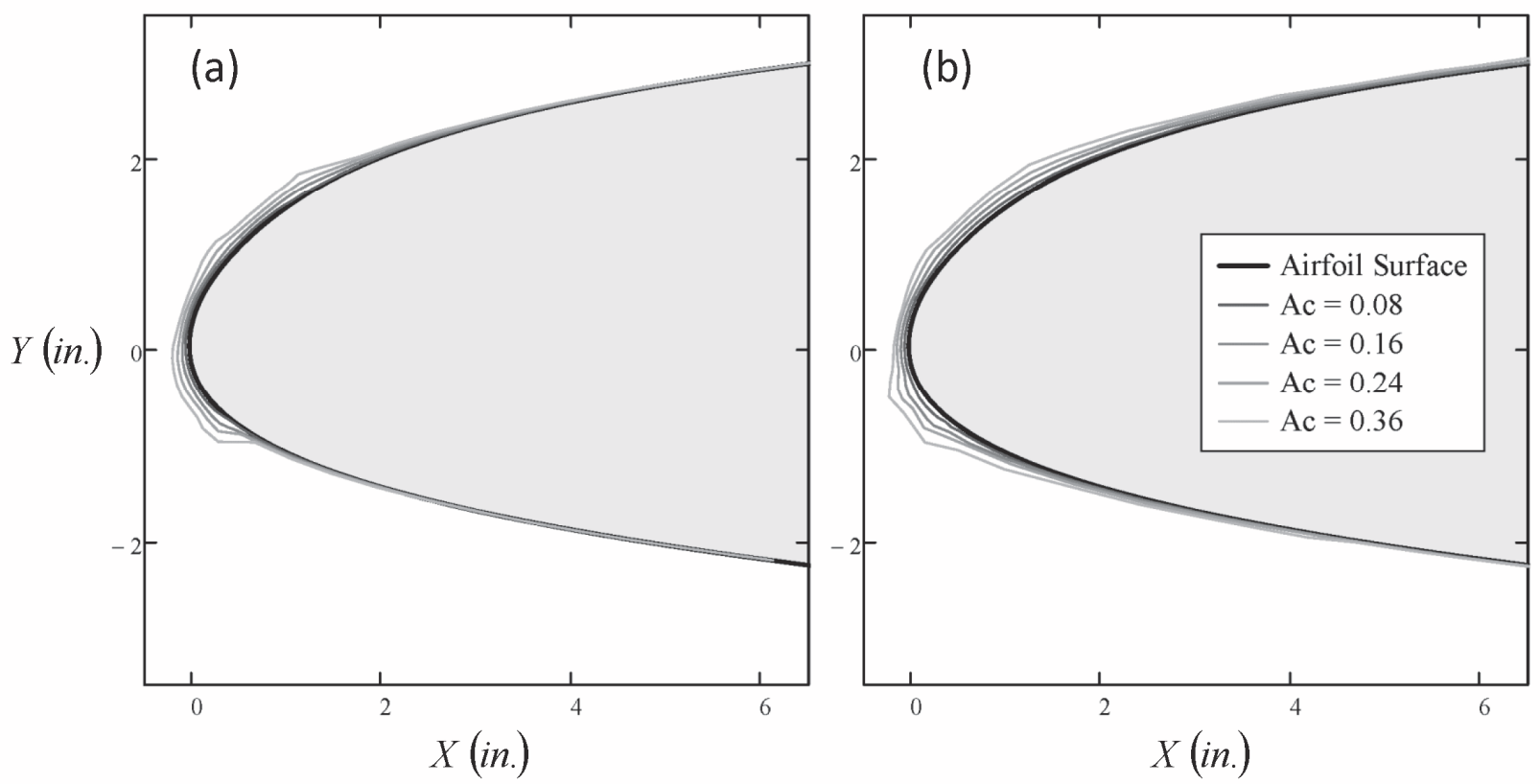

Figure 7. The Mean Ice Thickness Variations Presented in Airfoil Coordinates: (a) Appendix C and (b) SLD
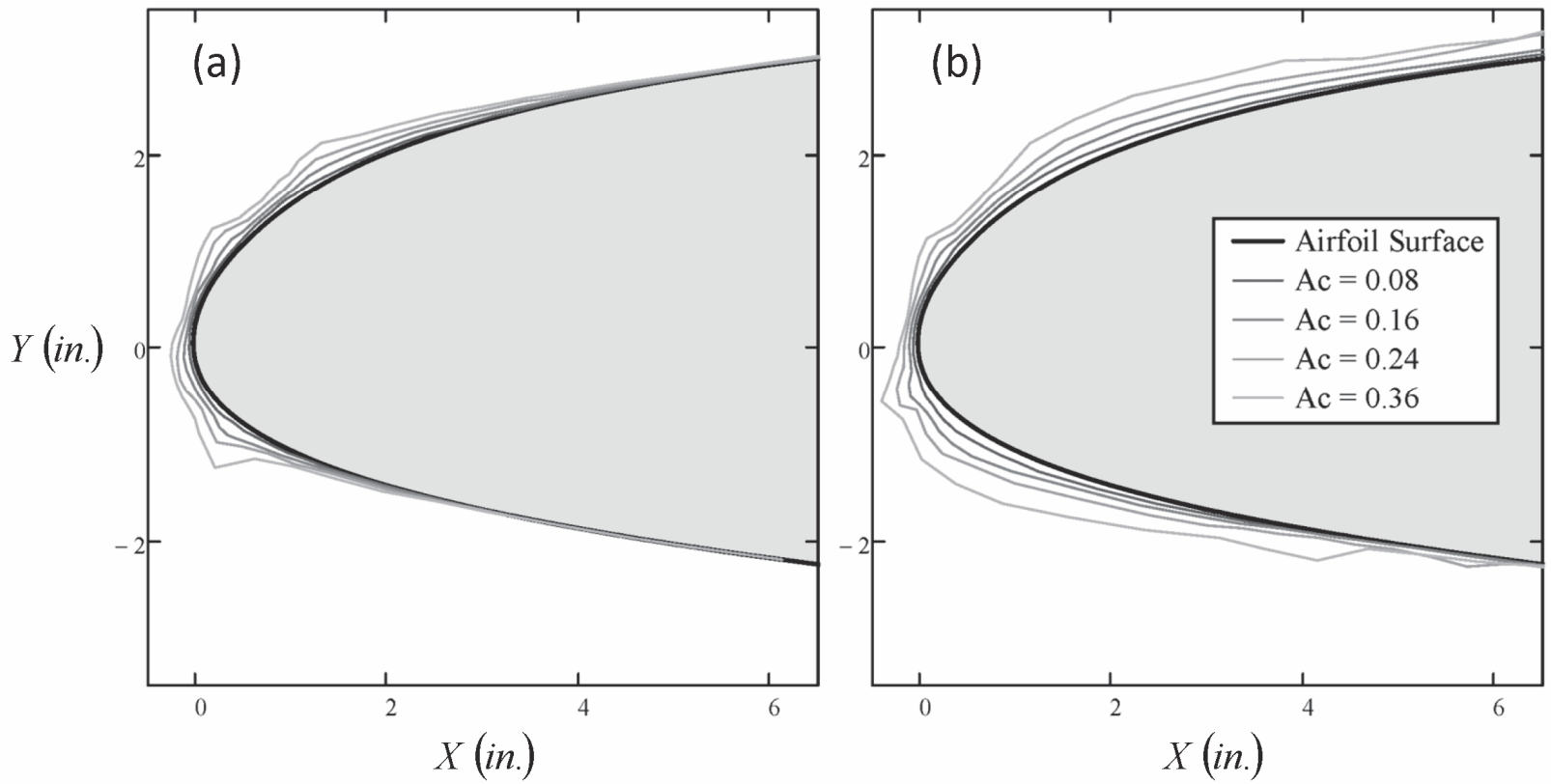

Figure 8. The 99.9\% Ice Thickness Variations Presented in Airfoil Coordinates: (a) Appendix C and (b) SLD 

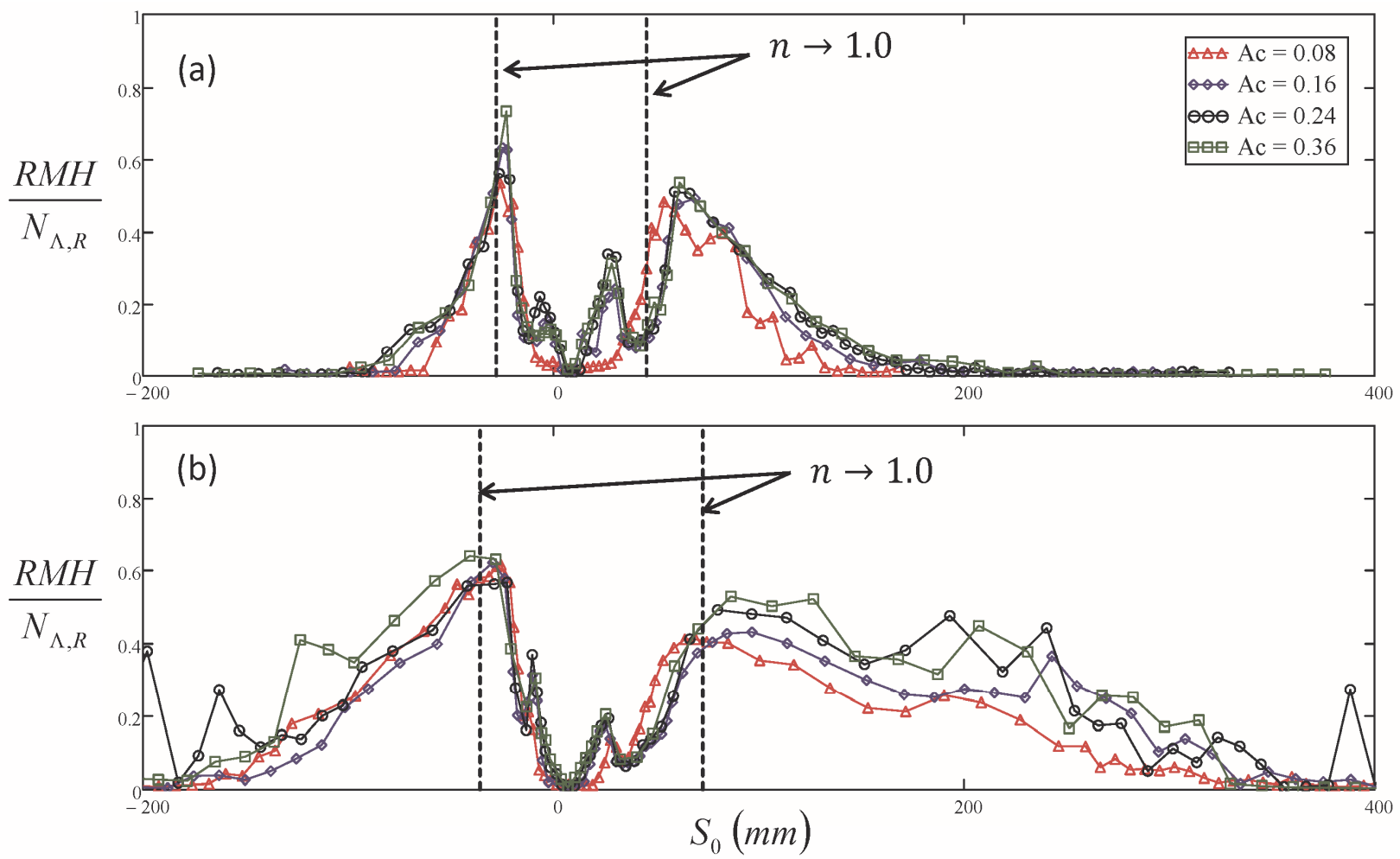

Figure 9. 99\%-Roughness Maximum Heights Scaled by Theoretical Attachment-Line Rime Thickness: (a) Appendix $C$ and (b) SLD
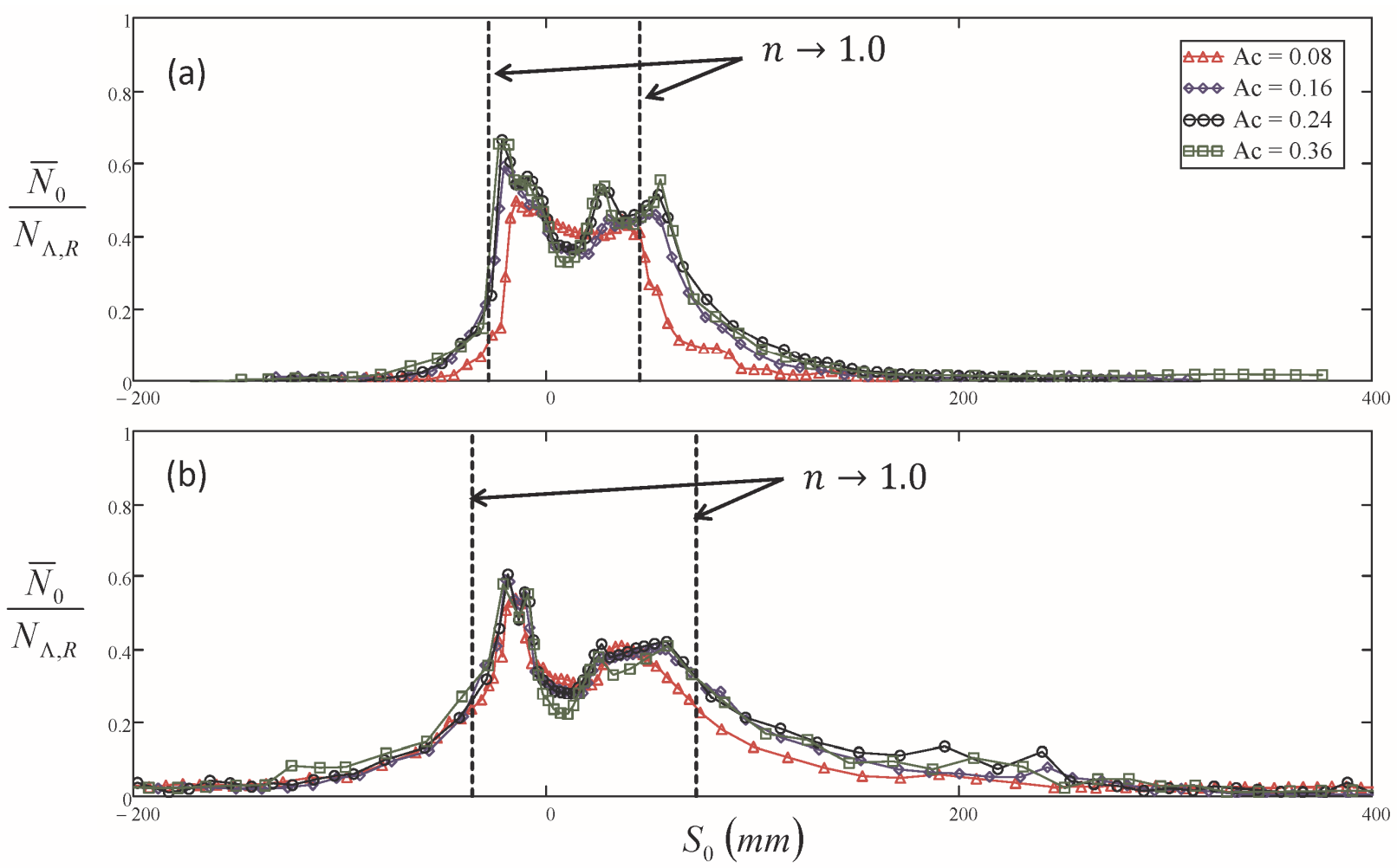

Figure 10. Mean Ice Thickness Scaled by Theoretical Attachment-Line Rime Thickness: (a) Appendix C and (b) SLD 

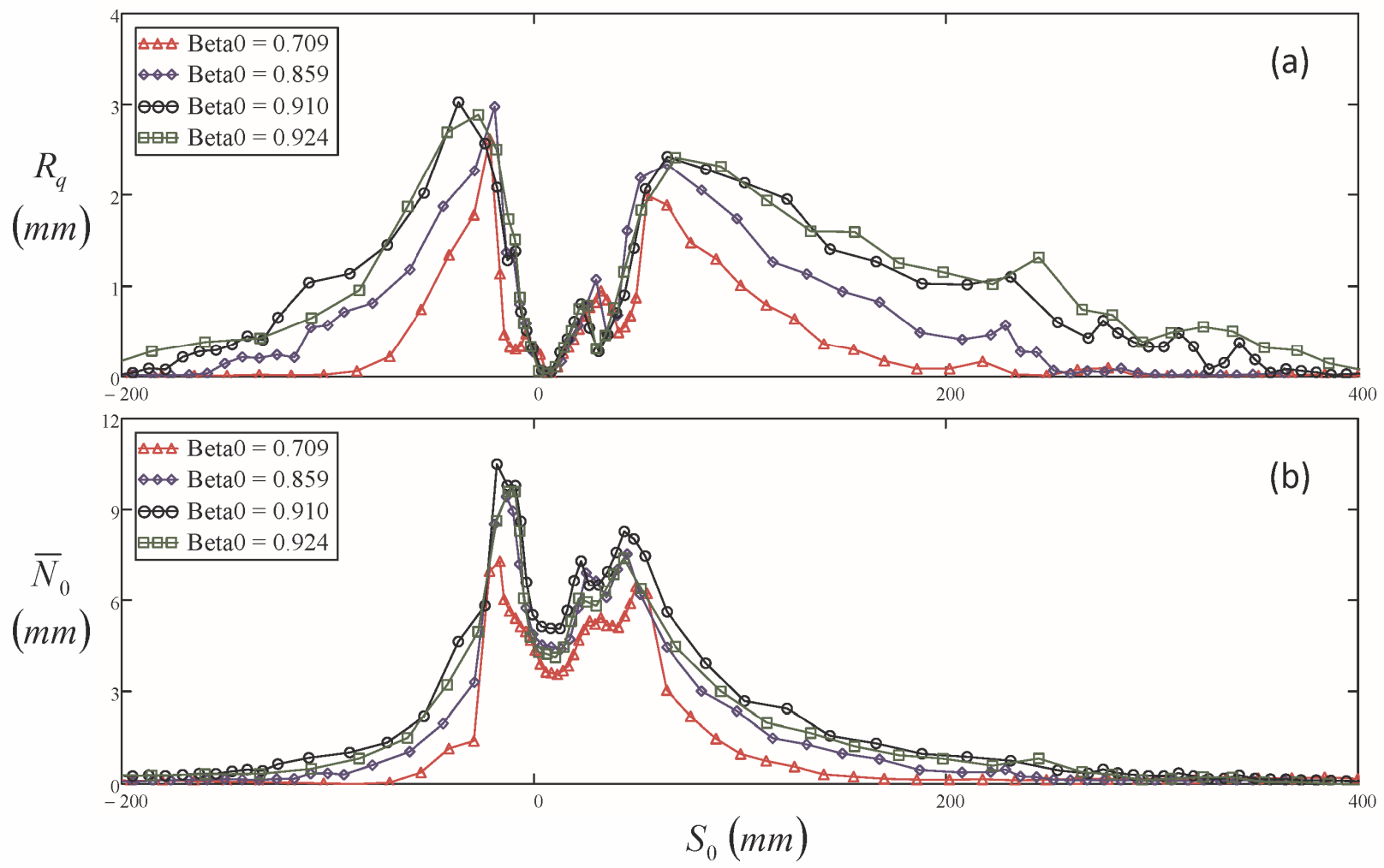

Figure 11. Raw Measurements for the Scaling Cases: (a) Roughness and (b) Thickness
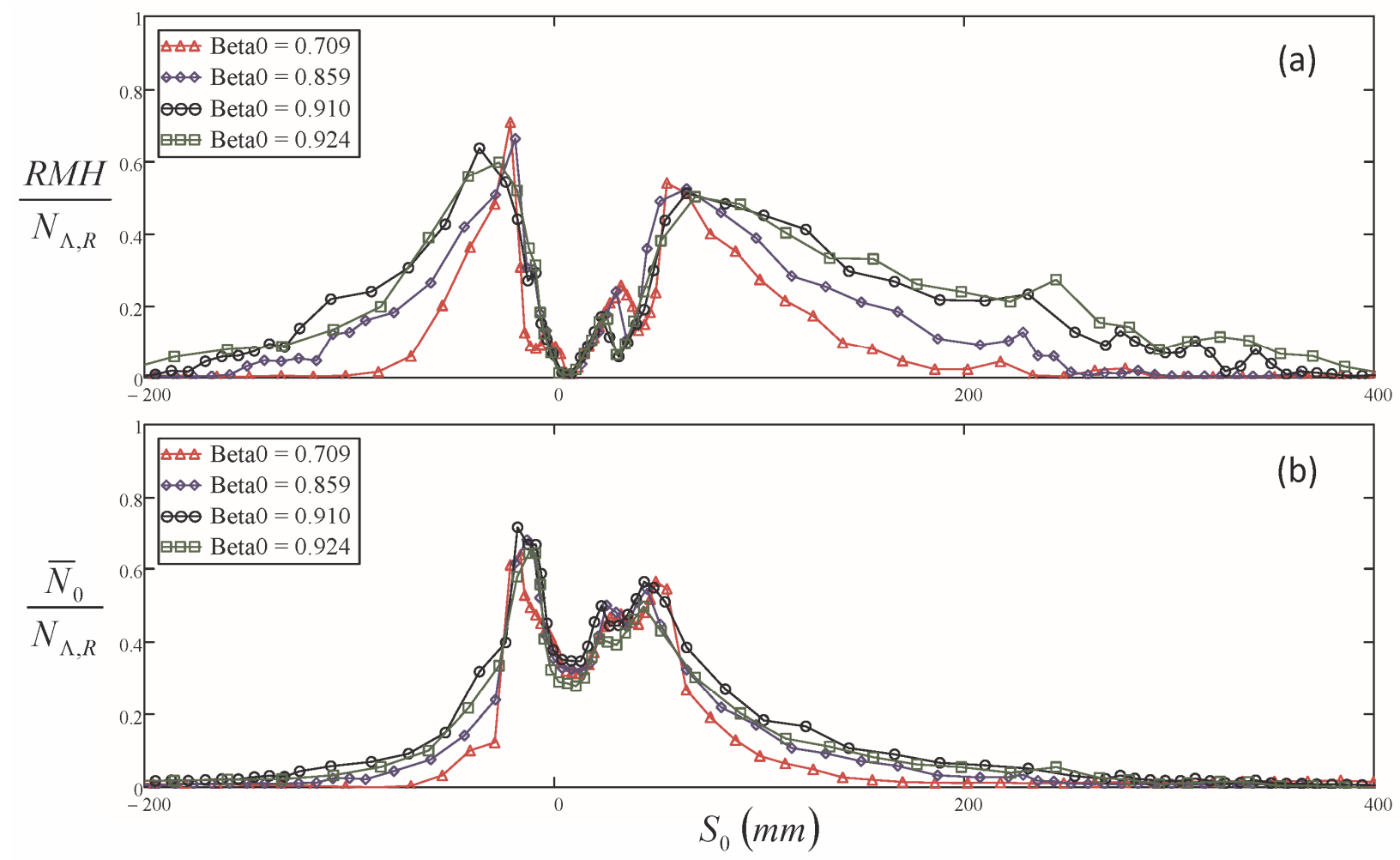

Figure 12. Normalized Ice Measurements for the Scaling Cases: (a) Roughness and (b) Thickness 


\section{Spatial Variations}

Following the approaches of McClain et al. [11] and McClain et al. [12], the spatial variations in roughness and thickness were explored using the local collection efficiency. For this study, the LEWICE predictions of local collection efficiency were employed to provide insight into the spatial variations along the asymmetric airfoil shape.

Before presenting the spatial scalings of a group of cases, such as all of the $\mathrm{We}_{d^{d}}$-scaled cases, a single case is presented to identify and illustrate physics resulting in the roughness and thickness spatial variations. Figure 13 presents the relative roughness and relative thickness variations along the HAARP-II model surface for the 012417.08 case based the local collection efficiency predicted using LEWICE. The 012417.08 point cloud is depicted in Figure 4(b), and the LEWICE predictions of collection efficiency and freezing fraction for the 012417.08 case are presented in Figure 2.

The abscissas for Figures 13(a) and 13(b) are 1- $\beta_{s} / \beta_{0}$, where $\beta_{s}$ is the local LEWICE collection efficiency and $\beta_{0}$ is the stagnation collection efficiency from Eq. (1). This choice of abscissa results in the far left each represents the stagnation point of the airfoil, while the far right represents the point on the airfoil where the surface no longer collects any of the droplets of the cloud. Based on this definition for the abscissa, a diagonal line has been added to Figure 13(a), which represents the ideal rime ice thickness variation along the surface.
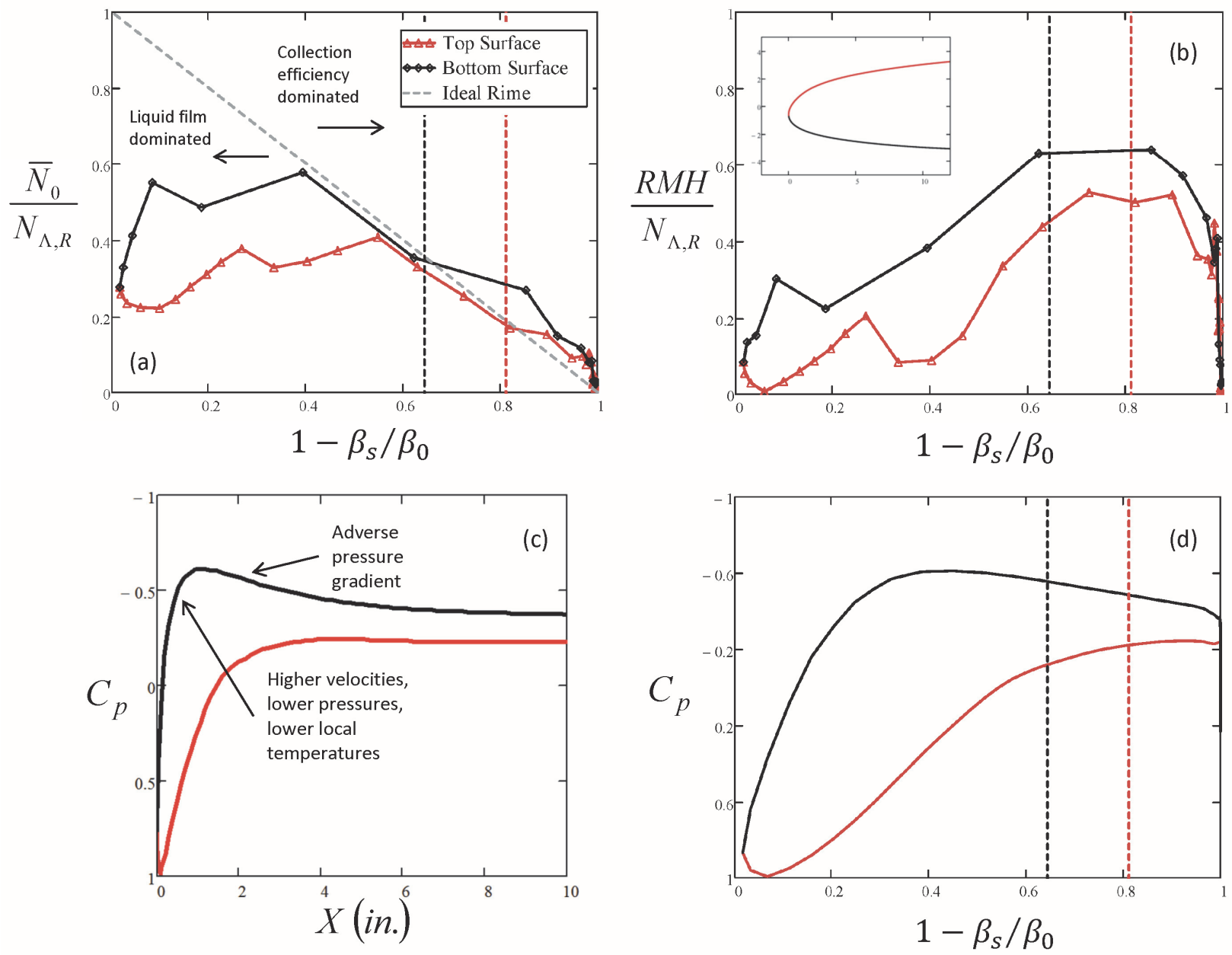

Figure 13. Normalized Surface Variations for the 012417.08 Case: (a) Normalized Thickness, (b) Normalized Roughness, (c) Pressure Coefficient Variations in Leading Edge Region in X-Coordinates, and (d) Pressure Coefficient Variations in Collection Efficiency Coordinates

The most significant difference in Figures 13(a) and 13(b) from what would be expected for a symmetric airfoil is the asymmetry in the roughness and thickness variations. In Figure 13, the red points and curves represent data on the top surface of the airfoil, while points and curves in black represent information on the bottom surface of the 
airfoil, as indicated on the inset of Figure 13(b). For symmetric airfoils, the top and bottom data would be expected to collapse into one profile. Figures 13(a) and 13(b) further demonstrate the asymmetry of the thickness and roughness profiles along the surface as indicated by the collection efficiency. In Figure 13(a), the average thickness on the bottom of the airfoil is larger than the average ice thickness on the top side of the airfoil near the leading edge region where the physics is expected to be dominated by the liquid film mechanics of a glaze-ice accretion process. However, as the collection efficiencies decrease, the relative thickness values approach the ideal rime line, and the top and bottom thickness profiles collapse and follow the ideal-rime trend.

Figure 13(b) demonstrates that the roughness variations on the top and bottom surfaces of the airfoil are similar in that there is a region of small isolated roughness that increases as the collection efficiency decreases. The roughness levels reach a maximum then decay rapidly as the collection efficiencies approach zero. While the variations on the top and bottom surfaces are similar, the roughness values on the bottom of the airfoil are larger than the values on the top surface of the airfoil for a specific value of collection efficiency. Further, the values of maximum roughness on either side of the model are similar in magnitude to the corresponding maximum thickness values on the respective side of the airfoil.

Figure 13(c) presents the pressure coefficient variation along the surface of the HAARP-II airfoil at $-1.9^{\circ}$ angle of attack as determined using a vortex panel solver, where the pressure coefficient is defined in Eq. (12) for Mach numbers close to zero.

$$
C_{p}=\frac{P-P_{S}}{\frac{1}{2} \rho U_{\infty}^{2}}=1-\left(\frac{U_{e}}{U_{\infty}}\right)^{2}
$$

Figures 13(c) shows that the $C_{p}$ values on the bottom surface are more negative, indicating lower surface pressures. These lower static pressures result in higher velocities and lower local air temperatures. Figure 13(d) presents the pressure coefficients along the surface versus $1-\beta_{s} / \beta_{0}$ as was used for Figures 13(a) and 13(b). Figure 13(d) indicates that the larger thickness values in the liquid film-dominated region, left side of Figure 13(a) are a result of the lower pressures. That is, while the velocities and resulting surface shear are higher, the lower surface pressures allow the liquid film to be thicker for a given collection efficiency resulting in more liquid water staying in the stagnation region as opposed to flowing downstream along the model surface. However, as the pressures decrease along the stream wise direction, the temperatures become low enough for the ice to accrete in a rime-like process, demonstrated by the collapse of the thickness profiles onto the ideal-rime line. The thickness trend on the bottom surface of the model approaches the ideal-rime line at a location further upstream than on the top surface of the model because the local temperatures are lower than the equivalent location on the bottom surface with the same collection efficiency.

To investigate the transition from a glaze-ice region to the rime-ice region indicated in Figure 13(a), the vertical dashed lines in Figures 13(a) and 13(b) indicate the locations along the airfoil surface where the freezing fraction values predicted by LEWICE rapidly approached a value of 1.0, as exhibited in Figure 2. The vertical lines indicating the locations where the freezing fractions reach values of 1.0 are also indicated in Figures 9 and 10. Since all of the Appendix C cases and all of the SLD cases have the same respective cloud conditions and since the LEWICE simulations were all run using a single time step, the locations where the freezing fraction reaches 1.0 are the same for each basic cloud condition.

At the $n=1.0$ location in Figures 9, 10, and 13, the ice accretion process is thought to transition from a glaze process upstream of the $n=1.0$ location, which would exhibit a liquid film, to a rime process downstream of the $n=$ 1.0 location. Consequently, the $n=1.0$ location was expected to correlate to the locations of maximum ice thickness on each side of the airfoil in Figure 10 and the location of the glaze-to-rime transition in Figure 13(a). Inspecting Figures 9, 10 and 13, the $n=1.0$ location appears most closely related to the location of maximum roughness on either side of the airfoil. However, the fact that the LEWICE simulations were performed using one time-step, that is, using information primarily based on the clean airfoil, must be considered in interpreting the freezing fraction limit locations and their implications regarding roughness and ice thickness evolution. Better agreement between the locations of the glaze-to-rime transition may be achieved by running LEWICE using multiple timesteps, especially for the longer ice accretion cases $\left(A_{c}>0.2\right)$.

To provide insight into interactions of collection efficiency and freezing fraction in unskewed geometric coordinates, Figure 14(a) and 14(b) present the X-Y projections of the point clouds shaded by the local collection efficiency and local freezing fraction, respectively, as predicted using LEWICE. In Figure 14, the point clouds have been rotated by $1.9^{\circ}$ to reflect the angle of attack relative to the horizontal direction. Further, Figure 15 presents the 
freezing fraction information of Figure 14(b) on the point cloud which has been unwrapped and rotated about the surface $\left(S_{0}\right)$ direction to reveal the roughness of the ice shape.

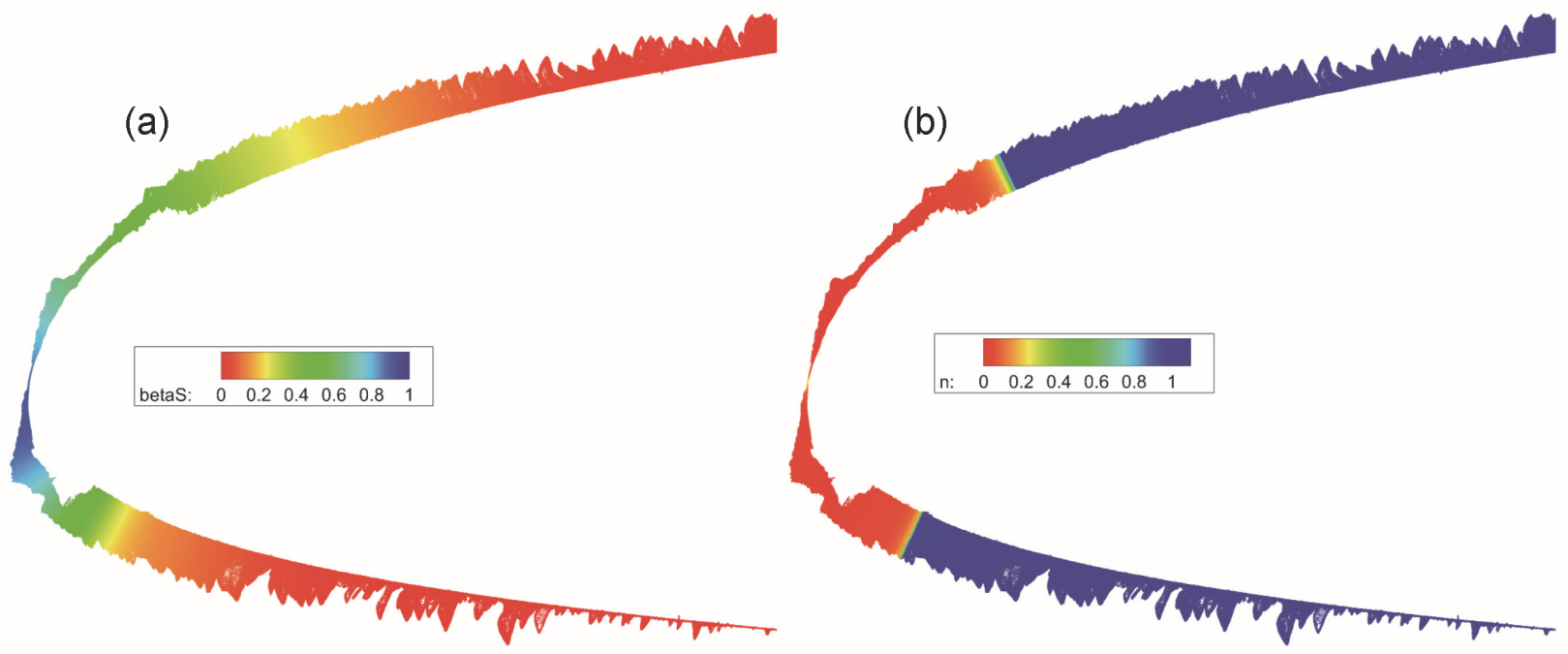

Figure 14. X-Y Projection of 012417.08 Point Cloud Shaded using LEWICE Predictions of (a) Local Collection Efficiency, and (b) Local Freezing Fraction
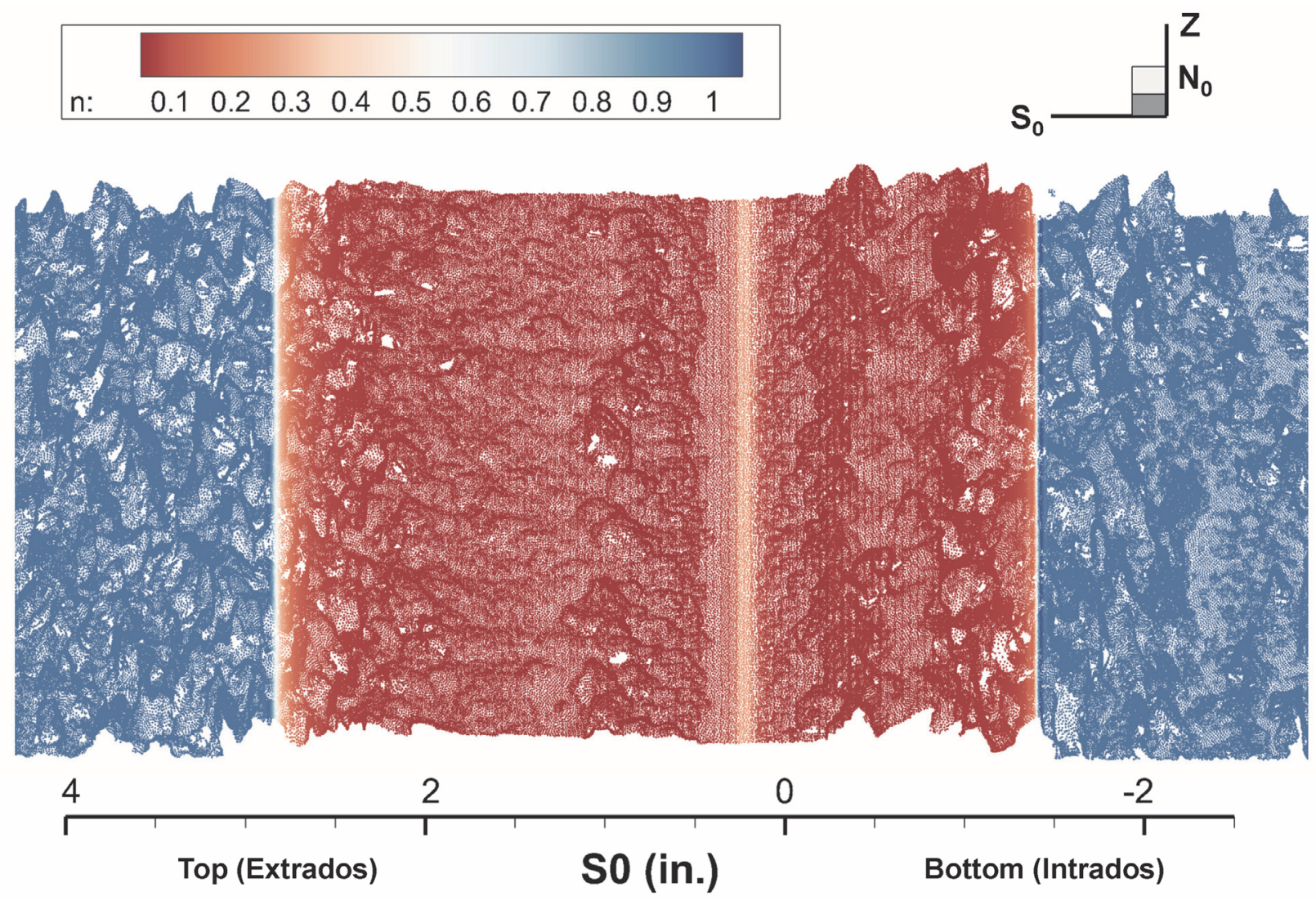

Figure 15. Unwrapped View of Leading Edge of Leading Edge Thickness for Case 012417.08 Shaded using Local Freezing Fraction Predicted by LEWICE 
Figures 14 and 15 demonstrate the complex interaction between the local collection efficiency and the freezing fraction and the resulting roughness along the airfoil. When considered with Figure 2, Figure 14 demonstrates that the freezing fraction abruptly increases to 1.0 in a region where the collection efficiency is decreasing to levels less than 0.4. In the region near the freezing fraction change, the plateau region ends and the roughness increases drastically. Figure 15 provides further evidence of the transition from a glaze-icing process to a rime-like process in that near the stagnation point is a smooth region. A line of roughness elements resembling a ridge follows downstream of the stagnation region on either side of the airfoil and leading to a plateau of smoother, rivulet-like channels. Then near the $n \rightarrow 1$ location, the plateau region ends leading to an area of large roughness elements which decay in size and number moving further from the stagnation point.

While the one time-step LEWICE predictions of freezing fraction may not exactly reflect the freezing fractions on the ice roughened airfoil, the liquid film stability and breakdown could also be the cause of the difference between the edge of the ice plateau and the $n \rightarrow 1$ location. That is, the edge of the plateau may be set based on the location where the shear rates become high enough and the collection efficiency becomes low enough that the liquid film on the surface of the ice becomes unstable and breaks down. This cause of the ice plateau was postulated in Refs. [6, 7, 11, and 12]. Interestingly, Figure 15 could be interpreted as showing two roughness regions downstream of the ice plateau. The first region downstream of the plateau region would still have some liquid film and would be expected to exhibit glaze-ice qualities. Downstream of the $n \rightarrow 1$ location, the roughness would exhibit rime-ice characteristics such as feather roughness. While this phenomenon is possible, evidence of a change in roughness characteristics is not readily apparent in Figure 15.

Figure 16 presents the scaled spatial variation figures for the $\mathrm{We}_{d}$-matched cases, using the same scaling axes as was used for Figure 13(a) and 13(b). Figure 16 demonstrates the combined ideal-rime ice temporal scaling on the vertical axis with the collection efficiency spatial scaling collapses the thickness and roughness variations on the respective sides of the HAARP-II model and reflects the same physics indicated in Figure 13. The case that most deviates from the other cases is the 012417.01 case $\left(\beta_{0}=0.709\right)$, which is the only Appendix C case with an MVD $=$ $42 \mu \mathrm{m}$.
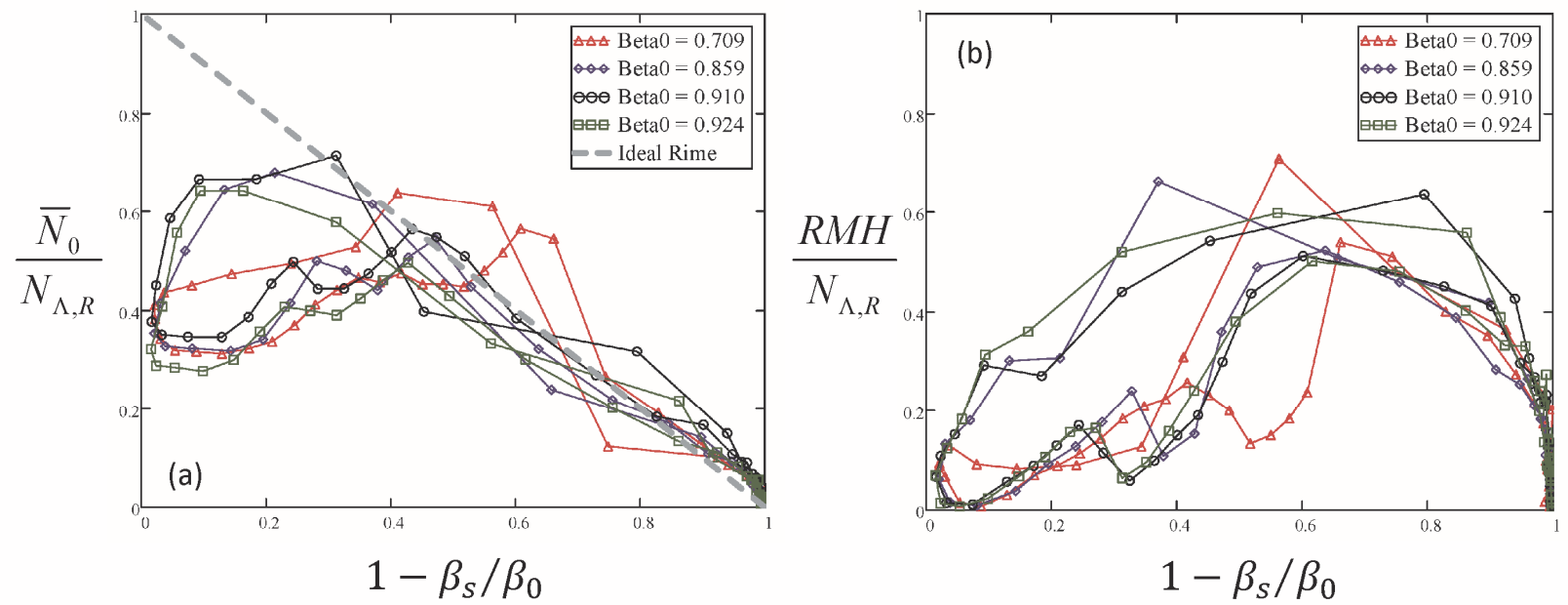

Figure 16. Scaled Thickness and Roughness Values versus Local Collection Efficiency for We a $^{-M a t c h e d}$ Cases: (a) Mean Thickness and (b) 99\% Roughness Maximum Height

Figure 17 presents the scaled thickness variations versus the local collection efficiency for the time-progression cases. Figure 17(a) presents the Appendix C cases, while Figure 17(b) presents the SLD cases. Figure 17(b) demonstrates that the SLD cases collapse in both the glaze and rime regions, and in the rime region, the cases follow the ideal-rime trend. Figure 17(a), however, shows that the Appendix C cases generally collapse, with the exception of the shortest ice accretion case $\left(A_{c}=0.08, \Delta t_{s}=85 \mathrm{~s}\right)$, but the profiles are slightly higher than the idea-rime trend in the rime-region.

Figure 18 presents the scaled roughness variations versus the local collection efficiency for the time-progression cases. Following the approach of Figure 17, Figure 18(a) presents the Appendix C cases, while Figure 18(b) presents the SLD cases. Figures 18(a) and 18(b) demonstrate similar features and trends; however, the roughness profiles for the Appendix $\mathrm{C}$ cases appear shifted to the right-side. 
When considering the shift to the right in Figure 18(a), the deviations from the ideal-rime trend in Figure 17(a), and the deviation of the Appendix $\mathrm{C}$ case for the $\mathrm{We}_{d}$-matched cases in Figure 16, the results may indicate an issue with LEWICE's prediction of the local collection efficiency for the Appendix C cases. Two possible causes of maybe 1) the 7-bin distribution may be insufficient to properly capture the surface collection efficiency variations or 2) since the roughness and thickness regions are more compact (in a smaller region) near the stagnation point for the Appendix C cases, as demonstrated in Figure 4, the local collection efficiencies predicted using a one time-step prediction in LEWICE are less appropriate than for the SLD cases. However, these explanations are counter to other LEWICE validation results [30], which indicate that LEWICE and the 7-bin distribution method should be better at capturing Appendix C accretion events compared to SLD accretion events.
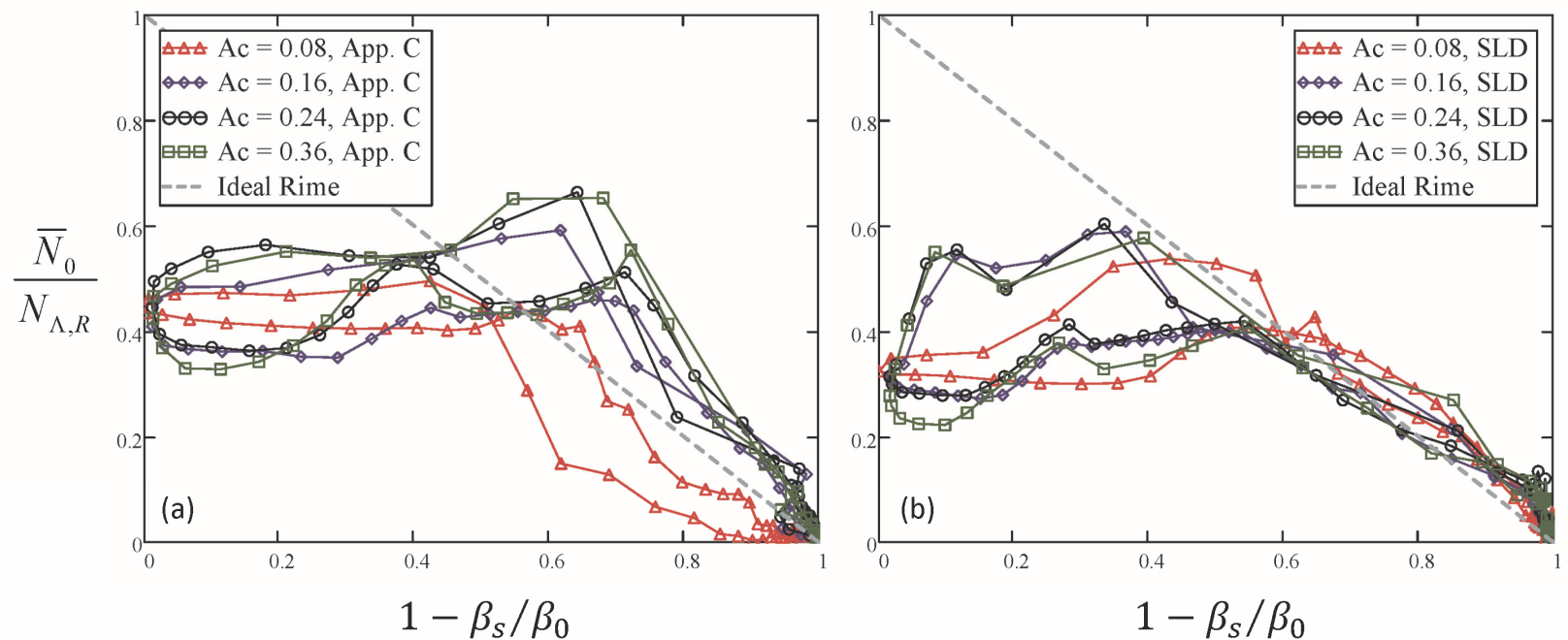

Figure 17. Scaled Mean Ice Thickness versus Local Collection efficiency for the Time Progression Cases: (a) Appendix C Cases and (b) SLD Cases
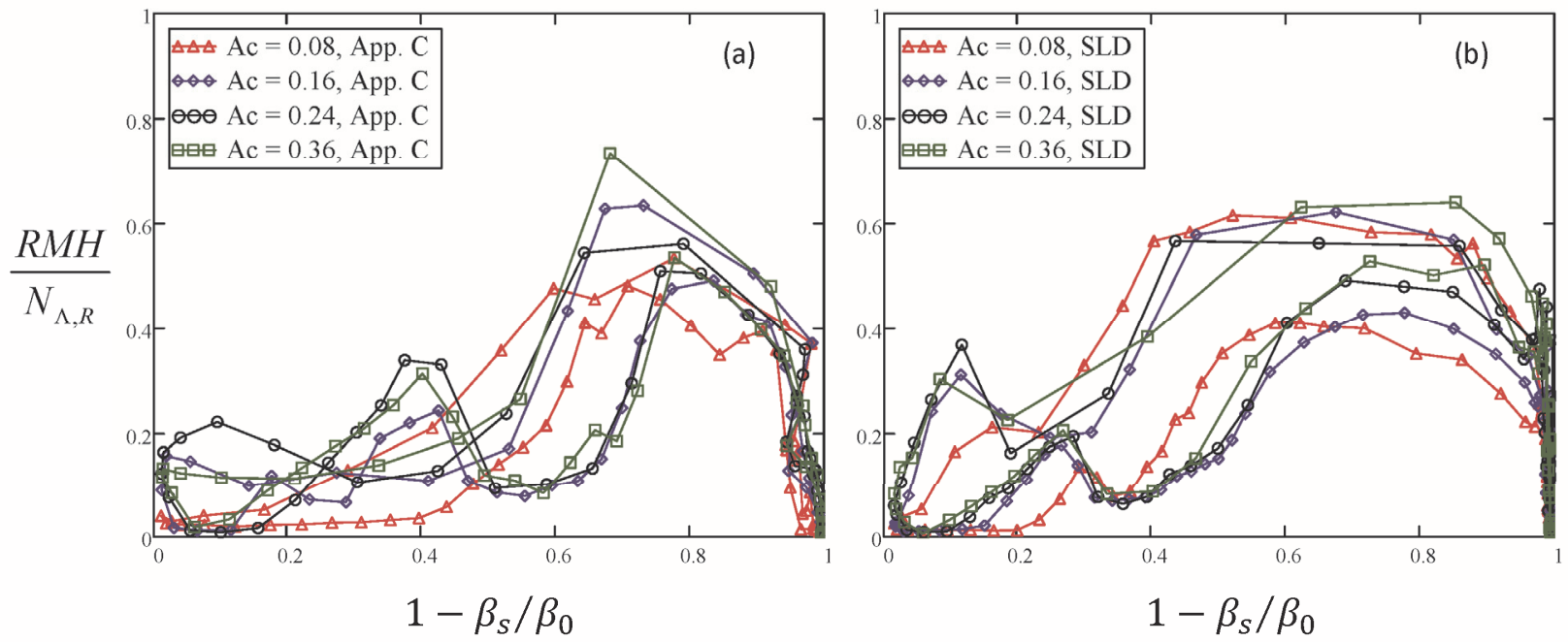

Figure 18. Scaled 99\%-Roughness Maximum Height versus Local Collection efficiency for the Time Progression Cases: (a) Appendix C Cases and (b) SLD Cases

While the Appendix C cases appear to be skewed from the ideal-rime trends and from the SLD cases, Figures 13-16 are encouraging for the development of a correlation for roughness evolution based on the temporal and spatial scalings employed and based on knowledge of the location where the freezing fraction approaches 1.0 indicating the transition to a rime-like ice accretion process. However, given the demonstrated influence of the 
location of the freezing fraction increase $(n \rightarrow 1)$, indicating a possible local glaze-to-rime ice accretion process transition, the influence of freestream temperature on roughness and thickness evolution must be explored in future studies. In the cases included in this study, the stagnation point freezing fraction $\left(n_{0}\right)$ ranged from 0.217-0.25. As the static temperatures become colder, the local transition from glaze-to-rime is expected to shift towards the stagnation point on the model. As the static temperatures decrease, the thickness variations should approach the ideal-rime trend with collection efficiency nearer to the stagnation point. The effect the earlier glaze-to-rime transition will have on the roughness surface variations is not known regarding the maximum values of roughness or the location of where the maximum values of roughness occurs.

Another area for future investigation includes the effect of lifting angles of attack and the circulation imposed on the freestream inviscid flow. One interesting observation regarding the LEWICE simulations depicted in Figures 2 and 14(a) is that for the asymmetric HAARP-II model, the maximum collection efficiency does not occur at the stagnation point on the model because of the large droplet sizes and the resulting non-Stokes behavior of the droplets deviating from the flow streamlines in the stagnation region. As the angle of attack changes, the difference between the location of maximum collection efficiency and the stagnation point will change. How the changes in the angle of attack will affect the early ice roughness evolution is currently unknown.

\section{Conclusions}

Experiments were performed in the IRT to investigate the ice roughness and thickness evolution on a small business-jet wing model with airfoil characteristics similar to those expected for future generation aircraft. The experiments include icing-event time progressions in both Appendix C and SLD conditions as well as a set of $\mathrm{We}_{d^{-}}$ matched cases expanding a previous study on symmetric airfoils. All of the cases presented were performed at the no-lift angle of attack $\left(-1.9^{\circ}\right)$ for the model so that the effects of inviscid freestream flow circulation could be minimized enabling the best comparison to the prior studies of ice roughness and thickness evolution on symmetric airfoils.

The roughness and thickness measurements were reduced using temporal scaling methods, and spatial variations were investigated using LEWICE predictions of the local collection efficiency and local freezing fraction. The primary findings of the study are:

1) The asymmetry in the airfoil shape and the resulting differences in the local pressure, temperature, collection efficiency, and freezing fraction led to significant differences in the ice thickness and roughness variations along the top and bottom surfaces of the model.

2) The use of the ideal-rime ice thickness as a temporal scaling factor collapses the roughness and thickness variations in the stagnation regions of the ice profiles which are expected to form in a glaze-ice accumulation process. While the thickness and roughness profiles are asymmetric about the stagnation point, the temporal scaling results are similar to those found on symmetric airfoils.

3) When the spatial scaling based on local collection efficiency is used to present the scaled thickness variations along the airfoil, the profiles indicate two distinct regions of the ice accretion: 1) a region where the liquid-film is present and the ice accretion is assumed to follow a glazed icing process and 2) a region where the ice varies in a manner expected for a rime accretion.

4) While the thickness and roughness profiles are asymmetric about the stagnation point, the temporal and spatial scaling results are similar to those found on symmetric airfoils.

5) When the LEWICE predictions of local freezing variation were used to explore the roughness and thickness variations, the location on the airfoil surface where the freezing fraction rapidly approaches a value of 1.0 occurs downstream of the thickness plateau and most closely corresponds with the location of maximum ice roughness. However, the LEWICE predictions used in this study were performed using one-time step, and consequently, represent the initial conditions on the clean airfoil.

The study represents the first study of ice roughness evolution on asymmetric airfoils. Future studies are planned to investigate the influence of the freestream static temperature and resulting stagnation point freezing fractions on the roughness evolution and spatial variations. Further, since future generation aircraft will most certainly change angles of attack during flight, future studies are planned to investigate the influence of angle of 
attack and the resulting circulation imposed on the inviscid freestream flow on the roughness evolution and spatial variations.

\section{Acknowledgments}

The efforts reported in this paper were partially supported as part of NASA Collaborative Agreement No. NNX16AN32A through the Advanced Air Transport Technology (AATT) program. The authors thank Mr. Richard E. Kreeger, Mrs. Laura King-Steen, Mr. Quentin Schwinn, Ms. Jordan Salkin, and Dr. Sam Lee for their assistance with the study. Any opinions presented in this paper are those of the authors and do not reflect the views of NASA or the United States government.

\section{References}

${ }^{1}$ Shin, J.,(1994), “Characteristics of Surface Roughness Associated With Leading Edge Ice Accretion,” NASA TM-106459.

${ }^{2}$ Anderson, D. N., and Shin, J., (1997), “Characterization of Ice Roughness from Simulated Icing Encounters,” NASA TM107400

${ }^{3}$ Anderson, D. N., Hentschel, D. B., and Ruff, G. A., (1998), “Measurement and Correlation of Ice Accretion Roughness,” NASA CR-2003-211823

${ }^{4}$ Lee, S., Broeren, A., Addy, H., Sills, R., and Pifer, E., (2012), "Development of 3D Ice Accretion Measurement Method," AIAA-2012-2938, presented at the $4^{\text {th }}$ AIAA Atmospheric and Space Environments Conference, June 25-28.

${ }_{5}^{5}$ Lee, S., Broeren, A. P., Kreeger, R. E., Potapczuk, M., and Utt, L., (2014), "Implementation and Validation of 3-D Ice Accretion Measurement Methodology," 6th AIAA Atmospheric and Space Environments Conference, June 16-20, Atlanta, GA, AIAA-2014-2613.

${ }^{6}$ McClain, S. T. and Kreeger, R. E., (2013), “Assessment of Ice Shape Roughness Using a Self-Organizing Map Approach,” Presented at the 5th AIAA Atmospheric and Space Environments Conference, June 24-27, San Diego, CA, AIAA-2013-2546.

${ }^{7}$ McClain, S.T., Reed, D., Vargas, M., Kreeger, R.E., and Tsao, J.-C.,, (2014), "Ice roughness in Short Duration SLD Icing Events," Presented at the 6th AIAA Atmospheric and Space Environments Conference, June 16-20, Atlanta, GA, AIAA-20142330.

${ }^{8}$ McClain, S.T., Vargas, M., Kreeger, R.E., and Tsao, J.-C., (2015), “A Reevaluation of Appendix C Ice Roughness Using Laser Scanning," SAE 2015 International Conference on Icing of Aircraft, Engines, and Structures, June 22-25, Prague, Czech Republic, SAE2015-01-2098.

${ }^{9} 14$ CFR, Aeronautics and Space, Part 25 Airworthiness Standards: Transport Category Airplanes, Section C25.1: Appendix C;" published by the Office of the Federal Register, National Archives and Records Administration, Washington, DC., Amdt. 25140, effective 5-Jan-2015.

10“'14 CFR Parts 25 and 33: Airplane and Engine Certification Requirements in Supercooled Large Drop, Mixed Phase, and Ice Crystal Icing Conditions,” (2010), Federal Register, Vol. 75, No. 124, June 29, 37311-37339.

${ }^{11}$ McClain, S.T., Vargas, M., and Tsao, J.-C., (2016), "Characterization of Ice Roughness Variations in Scaled Glaze Icing Conditions," 8th AIAA Atmospheric and Space Environments Conference, June 13-17, Washington, DC, AIAA-2016-3592.

${ }^{12}$ McClain, S.T., Vargas, M., and Tsao, J.-C., (2017), "Ice Roughness and Thickness Evolution on a Swept NACA 0012 Airfoil," 9th AIAA Atmospheric and Space Environments Conference, June 5-9, Denver, CO, AIAA-2017-3592.

${ }^{13}$ Bruner, S. et al., (2010), "NASA N+3 Subsonic Fixed Wing Silent Efficient Low-Emissions Commercial Transport (SELECT) Vehicle Study: Revision A,” NASA Technical Report NASA/CR-2010-216798.

${ }^{14}$ Greitzer. E.M., et al., (2010), "N+3 Aircraft Concept Designs and Trade Studies - Volume I," NASA Technical Report CR2010-216794/VOL1.

${ }^{15}$ Greitzer. E.M., et al., (2010), "N+3 Aircraft Concept Designs and Trade Studies - Volume 2: Appendices-Design Methodologies for Aerodynamics, Structures, Weight, and Thermodynamic Cycles," Technical Report, NASA CR-2010216794/VOL2.

${ }^{16}$ Gundlach, J. F., Tetrault, P. A., Gern, F. H., Nagshineh-Pour, A. H., Ko, A., Schetz, J. A., et al., "Conceptual Design Studies of a Strut-Braced Wing Transonic Transport,” Journal of Aircraft, Vol. 37, No. 6, 2000, pp. 976-983.

${ }^{17}$ Gur, O., Bhatia, M., Schetz, J. A., Mason, W. H., Kapania, R. K., and Mavris, D. N., (2010) "Design Optimization of a

Truss-Braced-Wing Transonic Transport Aircraft," Journal of Aircraft, Vol. 47, No. 6, pp. 1907-1917.

${ }^{18}$ Gupta, R., Mallik, W., Kapania, R. K., and Schetz, J. A., (2014), "Multidisciplinary Design Optimization of Subsonic StrutBraced Wing Aircraft", 52nd Aerospace Sciences Meeting, AIAA SciTech, AIAA 2014-0186.

${ }^{19}$ Drela, M., (2011), "Development of the D8 Transport Configuration," 29th AIAA Applied Aerodynamics Conference, 2730 June, Honolulu, HI, AIAA-2011-3970.

${ }^{20}$ Pandya, S. A., (2012), "External Aerodynamics Simulations for the MIT D8 'Double Bubble' Aircraft Design," Seventh International Conference on Computational Fluid Dynamics, 9-13 July, Big Island, HI, ICCFD7-4304.

${ }^{21}$ Pandya, S. A., Uranga, A., Espitia, A., and Huang, A., (2014) "Computational Assessment of the Boundary Layer Ingesting Nacelle Design of the D8 Aircraft", 52nd Aerospace Sciences Meeting, AIAA SciTech, AIAA-2014-0907.

${ }^{22}$ Liebeck, R.H., (2004), "Design of the Blended Wing Body Subsonic Transport." Journal of Aircraft, Volume 41, Issue 1, January-February, pp. 10-25.

${ }^{23}$ Kim, H., and Liou, M., (2013), "Flow Simulation of N3-X Hybrid Wing Body Configuration,” AIAA-2013-0221, January. 
${ }^{24}$ Hyun, D. K., Felder, J. L., Tong, M. T., and Armstrong, M., (2013), "Revolutionary Aeropropulsion Concept or Sustainable Aviation: Turboelectric Distributed Propulsion," International Society for Air Breathing Engines, ISABE-2013-1719.

${ }^{25}$ Papadakis, M., Wong, S.-H., Yeong, H.-W., Wong, S.-C., and Vu, G.T., (2008), "Icing Tunnel Experiments with a Hot Air Anti-Icing System," AIAA-2008-444.

${ }^{26}$ Ruff, G.A., 1986, Analysis and Verification of the Icing Scaling Equations, AEDC-TR-85-30, vol. 1 (Rev), March 1986.

${ }^{27}$ Tsao, J.C. and Lee, S., "Evaluation of Icing Scaling on Swept NACA 0012 Airfoil Models," NASA/CR-2012-217419, May 2012.

${ }^{28}$ Tsao, J.C. and Kreeger, R.E., "Experimental Evaluation of Stagnation Point Collection Efficiency of the NACA 0012 Swept Wing Tip,” AIAA-2009-4125 and NASA/TM-2010-216102, March 2010.

${ }^{29}$ Langmuir, I. and Blodgett, K. B. "A Mathematical Investigation of Water Droplet Trajectories," Army Air Forces Technical Report No. 5418, February 1946.

${ }^{30}$ Wright, W., "User's Manual for LEWICE Version 3.2," NASA/CR-2008-214255, Nov. 2008.

${ }^{31}$ Steen, L.E., Ide, R.F., Van Zante, J.F., Acosta, W.J., "NASA Glenn Icing Research Tunnel: 2014 and 2015 Cloud Calibration Procedures and Results," NASA/TM-2015-218758, May 2015.

${ }^{32}$ Kohonen, T., (2001), Self-Organizing Maps, Berlin: Springer-Verlag, 3rd ed.

${ }^{33}$ McClain, S.T., (2016), "Manual Point Cloud Registration for Combined Ice Roughness and Ice Thickness Measurements," 8th AIAA Atmospheric and Space Environments Conference, June 13-17, Washington, DC, AIAA-2016-3590.

${ }^{34}$ Fujiwara, G.E.C., Bragg, M., Camello, S., and Lum, C., (2016), "Computational and Experimental Ice Accretions of Large Swept Wings in the Icing Research Tunnel," $8^{\text {th }}$ AIAA Atmospheric and Space Space Environments Conference, June 13-17, Washington, DC, AIAA-2016-3734. 